\title{
A Putative ABC Transporter Permease Is Necessary for Resistance to Acidified Nitrite and EDTA in Pseudomonas aeruginosa under Aerobic and Anaerobic Planktonic and Biofilm Conditions
}

\section{OPEN ACCESS}

Edited by:

Martin G. Klotz,

Queens College of The City University

of New York, USA

Reviewed by:

Michael L. Vasil,

University of Colorado School of

Medicine, USA

Akos T. Kovacs,

Friedrich Schiller University of Jena,

Germany

*Correspondence:

Daniel J. Hassett

daniel.hassett@uc.edu

${ }^{\dagger}$ These authors have contributed equally to this work.

Specialty section: This article was submitted to Microbial Physiology and Metabolism,

a section of the journal

Frontiers in Microbiology

Received: 07 December 2015

Accepted: 23 February 2016

Published: 01 April 2016

Citation:

McDaniel C, Su S, Panmanee W, LaU GW, Browne T, Cox K, Paul AT, Ko S-HB, Mortensen JE, Lam JS, Muruve DA and Hassett DJ (2016) A Putative

$A B C$ Transporter Permease Is Necessary for Resistance to Acidified Nitrite and EDTA in Pseudomonas

aeruginosa under Aerobic and Anaerobic Planktonic and Biofilm Conditions. Front. Microbiol. 7:291. doi: 10.3389/fmicb.2016.00291
Cameron McDaniel ${ }^{1+}$, Shengchang Su ${ }^{1+}$, Warunya Panmanee ${ }^{1}$, Gee W. Lau ${ }^{2}$, Tristan Browne ${ }^{1}$, Kevin Cox ${ }^{1}$, Andrew T. Paul ${ }^{1}$, Seung-Hyun B. Ko ${ }^{1}$, Joel E. Mortensen ${ }^{3}$, Joseph S. Lam ${ }^{4}$, Daniel A. Muruve ${ }^{5}$ and Daniel J. Hassett ${ }^{1,6 *}$

1 Department of Molecular Genetics, Biochemistry and Microbiology, University of Cincinnati College of Medicine, Cincinnati, $\mathrm{OH}$, USA, ${ }^{2}$ College of Veterinary Medicine, University of Illinois at Urbana-Champaign, Urbana, IL, USA, ${ }^{3}$ Diagnostic and Infectious Diseases Testing Laboratory, Cincinnati Children's Hospital Medical Center, Cincinnati, OH, USA, ${ }^{4}$ Department of Molecular and Cellular Biology, University of Guelph, Guelph, ON, Canada, ${ }^{5}$ Department of Medicine, University of Calgary, Calgary, AB, Canada, ${ }^{6}$ Department of Research Services, Cincinnati Veteran's Association Medical Center, Cincinnati, $\mathrm{OH}$, USA

Pseudomonas aeruginosa (PA) is an important airway pathogen of cystic fibrosis and chronic obstructive disease patients. Multiply drug resistant $P A$ is becoming increasing prevalent and new strategies are needed to combat such insidious organisms. We have previously shown that a mucoid, mucA22 mutant $P A$ is exquisitely sensitive to acidified nitrite $\left(\mathrm{A}-\mathrm{NO}_{2}^{-}, \mathrm{pH}\right.$ 6.5) at concentrations that are well tolerated in humans. Here, we used a transposon mutagenesis approach to identify PA mutants that are hypersensitive to $\mathrm{A}-\mathrm{NO}_{2}^{-}$. Among greater than 10,000 mutants screened, we focused on PA4455, in which the transposon was found to disrupt the production of a putative cytoplasmic membrane-spanning ABC transporter permease. The PA4455 mutant was not only highly sensitive to $\mathrm{A}-\mathrm{NO}_{2}^{-}$, but also the membrane perturbing agent, EDTA and the antibiotics doxycycline, tigecycline, colistin, and chloramphenicol, respectively. Treatment of bacteria with $\mathrm{A}-\mathrm{NO}_{2}^{-}$plus EDTA, however, had the most dramatic and synergistic effect, with virtually all bacteria killed by $10 \mathrm{mM} \mathrm{A-NO}{ }_{2}^{-}$, and EDTA ( $1 \mathrm{mM}$, aerobic, anaerobic). Most importantly, the PA4455 mutant was also sensitive to $\mathrm{A}-\mathrm{NO}_{2}^{-}$in biofilms. $\mathrm{A}-\mathrm{NO}_{2}^{-}$sensitivity and an anaerobic growth defect was also noted in two mutants $(\mathrm{rm} / \mathrm{C}$ and $w b p M$ ) that are defective in B-band LPS synthesis, potentially indicating a membrane defect in the PA4455 mutant. Finally, this study describes a gene, PA4455, that when mutated, allows for dramatic sensitivity to the potential therapeutic agent, $A-\mathrm{NO}_{2}^{-}$as well as EDTA. Furthermore, the synergy between the two compounds could offer future benefits against antibiotic resistant $P A$ strains.

Keywords: Pseudomonas aeruginosa, acidified nitrite, EDTA, biofilms, ABC transporter permease 


\section{INTRODUCTION}

A hallmark of two major airway diseases, chronic obstructive pulmonary disease (COPD) and cystic fibrosis (CF), is infection by the opportunistic Gram-negative, rod-shaped pathogen, Pseudomonas aeruginosa (PA). COPD is characterized by airway epithelial debridement, the primary cause of which is chronic smoking (Hassett et al., 2014). In contrast, CF is an autosomal recessive inherited disease resulting in mutations in the cystic fibrosis transmembrane regulator gene (CFTR) on chromosome 7 that affects the function of many organs including but not limited to the lung, liver, pancreas, intestine, skin, and testes (Boucher, 2002). However, with time, it is airway infection in CF that leads to pulmonary insufficiency and ultimately death of the patient at an average age of $\sim 39$ (MacKenzie et al., 2014). Complicating both diseases are in vivo mutations that occur in the $m u c A$ gene of $P A$, encoding an inner membrane spanning anti-sigma factor (Martin et al., 1993; Valderrey et al., 2010). The most common mutation, mucA22, is characterized by a deletion of a $G$ residue at base 430 , resulting in a truncated MucA protein of $\sim 15.8 \mathrm{kDa}$ (Martin et al., 1993); wild-type MucA is $21 \mathrm{kDa}$. Most notably, $m u c A$ mutations allow for the sigma factor $\mathrm{Alg} \mathrm{T}(\mathrm{U})$ (alternatively $\sigma^{\mathrm{E}}$ or $\sigma^{22}$ ) to transcribe genes involved in the regulation and production of a highly viscous exopolysaccharide known as alginate. The production of alginate allows for increased resistance to antibiotics (Hentzer et al., 2001; Murphy et al., 2008), phagocytic killing (Meshulam et al., 1984), and markedly decreases the overall pulmonary function in both COPD and CF patients, especially during exacerbations of both diseases (Govan and Deretic, 1996; Hassett et al., 2014). Often, multiple antibiotic classes including aminoglycosides, $\beta$ lactams, quinolones, macrolides, and polymyxins are used to combat such refractory infections, yet during chronic infections, frequent use of these antibiotics results in strains that develop resistance. Therefore, novel treatment strategies are needed to reduce or even completely eradicate such problematic organisms.

In 2006, our group reported an important and novel observation that slightly acidified nitrite $\left(\mathrm{A}-\mathrm{NO}_{2}^{-}\right)$at the $\mathrm{pH}$ resembling that of the CF airway surface liquid (6.3-6.5; Coakley et al., 2003; Yoon et al., 2006) killed mucoid PA in both planktonic and biofilm culture, in sterile CF airway transplant sputum, and the findings were also substantiated in a murine lung infection model (Yoon et al., 2006). A- $\mathrm{NO}_{2}^{-}$displayed no adverse effects on primary CF airway epithelia when used at levels 20-fold higher $(300 \mathrm{mM})$ than that required to kill mucoid PA (Yoon et al., 2006). Recent studies on $P A$ biofilms grown on CF primary epithelial cells showed that $\mathrm{A}-\mathrm{NO}_{2}^{-}$killed $P A$ biofilms, inhibited the activity of aminoglycosides, yet demonstrated synergy with colistomethate (Zemke et al., 2014, 2015). Toxicology studies using dogs and rats revealed that inhalation of nebulized $\mathrm{NaNO}_{2}$ for 28 days was well tolerated in rats and dogs at doses up to $19-20 \mathrm{mg} / \mathrm{kg}$ : doses where the no observed adverse effect level (NOAEL) was established (Major et al., 2010). In addition, from a human use standpoint, $\mathrm{NO}_{2}^{-}$is already used as a food preservative of red meats and a treatment for cyanide poisoning.
In this study, we first used a transposon (Tn) mutant approach to screen for PA mutants that demonstrate increased susceptibility to $\mathrm{A}-\mathrm{NO}_{2}^{-}$when compared to wild-type and a mucoid mucA22 mutant. From a panel of $\sim 10,000$ Tn mutants, we focused on a very sensitive mutant that had a Tn insertion in the $P A 4455$ gene, encoding a putative cytoplasmic membranespanning $\mathrm{ABC}$ transporter permease. ATP-binding cassette transporters (or $\mathrm{ABC}$ transporters) are members of a protein superfamily that are present throughout various phyla, ranging from bacteria to humans (Higgins, 1992). These proteins utilize ATP to import small molecules including nutrients, antibiotics, drugs, and a myriad of other molecules. The PA4455 mutant was extremely sensitive to A-NO $\mathrm{NO}_{2}^{-}$, EDTA and several antibiotics. We also found that two mutants unable to generate the B-band lipopolysaccharide/O-side chain, $r m l C$ and $w b p M$, are defective in anaerobic growth and demonstrate increased susceptibility to both $\mathrm{A}-\mathrm{NO}_{2}^{-}$and EDTA, and especially when the two reagents were combined. From a translational perspective, a means to target PA4455 with novel drugs could possibly enhance the overall efficiency of killing problematic $P A$ infections, especially those associated with CF and COPD.

\section{MATERIALS AND METHODS}

\section{Bacterial Strains and Growth Conditions}

The bacteria and all primers designed and used for PCR reactions used in this study are listed in Table 1. Organisms were grown in either Luria-Bertani broth (LB), LB-100 $\mathrm{mM} \mathrm{KNO}_{3}$ $(\mathrm{LBN}) \pm 50 \mathrm{mM}$ potassium phosphate, $\mathrm{pH} 6.5$ or Pseudomonas isolation agar (PIA). Aerobic cultures were grown at $37^{\circ} \mathrm{C}$ with shaking at $180 \mathrm{rpm}$ at a $1 / 10$ volume to total Erlenmeyer flask volume. Anaerobic cultures were grown in a Coy laboratories anaerobic chamber at $37^{\circ} \mathrm{C}$. Media were also solidified with $1.5 \%$ Bacto-agar. Frozen bacterial stocks were stored at $-80^{\circ} \mathrm{C}$ in a 1:1 mixture of $30 \%$ glycerol and stationary-phase bacterial suspension.

\section{Manipulation of Recombinant DNA and Genetic Techniques}

All plasmid and chromosomal nucleic acid manipulations were performed by standard techniques (Maniatis et al., 1982). Plasmid DNA was transformed into E. coli strain DH5 $\alpha$-MCR (Protein Express, Cincinnati, OH). To detect the presence of insert DNA, X-Gal (5-bromo-4-chloro-3indolyl- $\beta$-D-galactopyranoside; $40 \mu \mathrm{g} / \mathrm{ml}$ ) was added to agar media. Restriction endonucleases and T4 DNA ligase were used as specified by the vendor (Invitrogen/Gibco-BRL Corp., Gaithersburg, MD). Plasmid DNA was isolated using the QIAprep Spin Miniprep Kit (Qiagen) and restriction fragments were recovered from low melting point agarose gels. PCRs for genes of interest were performed by using Pfu DNA polymerase (BRL) and appropriate primers in an MJ Research thermal cycler, with 30 cycles of denaturation $\left(2 \mathrm{~min}, 94^{\circ} \mathrm{C}\right)$, annealing $\left(1 \mathrm{~min}, 54^{\circ} \mathrm{C}\right)$, and extension $\left(1 \mathrm{~min} 30 \mathrm{~s}, 72^{\circ} \mathrm{C}\right)$. Amplified DNA fragments were gel purified, cloned into pCR2.1 (Invitrogen), and sequenced. 
TABLE 1 | Bacterial strains, plasmids and oligonucleotides used in this study.

Strain, plasmid or oligonucleotide Description (relevant genotype or phenotype) or sequence $\left(5^{\prime}\right.$ to $\left.3^{\prime}\right)$

\section{E. coli}

$\mathrm{DH} 5 \alpha$

S17-1 $\lambda$ pir

\section{$P$. aeruginosa}

PAO 1

PA01 $\triangle M U C A$

PA4455::Tn-Gm ${ }^{r}$

PA4455::Gm

$\mathrm{rm} / \mathrm{C}$

rmd R1 05, R2 05

wbpM

PA4455::Gm (pUCP-PA4455)

PAO1::attB::PA4455-lacZ

\section{PLASMIDS}

pUCGM

pQF50

mini-CTX1

pEX100T-KS

pUCPPA4455

pHA531

pHA532

pHA533

pQF50-nark

mini-CTX1-PA4455-lacZ

pEX $\triangle \mathrm{PA} 4455:: \mathrm{Gm}$

pEX $\triangle$ OPABC::FRT-Gm

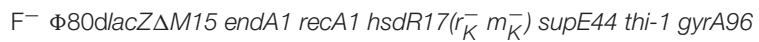

$\triangle$ (lacZYA-argF)U169

Pro- Res- Mod+recA; integrated RP4-Tet::Mu-Kan::Tn7, Mob+

Wild-type, prototroph

PAO1 deletion mutant of mucA gene

PAO1 transposon mutant

PAO1 $\triangle P A 4455:: G m$ insertion mutant

PAO1 derivative, $r m / C:: G m$ insertion, $A^{-} B^{-}$

PAO1 derivative, $r m d:: G m$ insertion, $\mathrm{A}^{-} \mathrm{B}^{+}$

PAO1 derivative, wbpM::Gm insertion, $\mathrm{A}^{+} \mathrm{B}^{-}$

Complemented PA4455::Gm mutant by plasmid-borne pUCP-PA4455

Promoter of PA4455 and lacZ transcriptional fusion was integrated at the chromosomal attB site of PAO1

Source, reference, or RE site

Invitrogen

Simon et al., 1983

Holloway et al., 1979

This study

This study

This study

Rahim et al., 2000

Rocchetta et al., 1998a,b

Creuzenet and Lam, 2001

This study

This study

\section{Schweizer, 1993}

Farinha and Helinski, 1990

Hoang et al., 2000

Schweizer and Hoang, 1995

Pseudomonas gene replacement suicide vector with modified multiple cloning site, sacB oriT, $\mathrm{Cb}^{\mathrm{R}}$

798 bp PA4455 gene cloned into EcoRl/BamHI sites of pUCP20, Ap ${ }^{R}$

This study

nirS::/acZ transcriptional fusion in $\mathrm{pQF50}, \mathrm{Ap}^{\mathrm{R}}$

nirQ::lacZ transcriptional fusion in $\mathrm{pQF50}, \mathrm{Ap}^{\mathrm{R}}$

norC::/acZ transcriptional fusion in $\mathrm{pQF50}, \mathrm{Ap}^{\mathrm{R}}$

nark promoter cloned into pQF50, Ap ${ }^{R}$

A 4-kb fragment containing promoter of PA4455 and lacZ fusion cloned into Xhol/Hindlll sites of the vector pmini-CTX1, Tc ${ }^{R}$

A 4-kb fragment containing flanking sequences of PA4455 and transposon insertion This study cassette cloned into Notl/Spel sites of pEX100T-KS, $\mathrm{Cb}^{R}, \mathrm{Gm}^{R}$

A 3-kb fragment containing flanking sequences of the operon from PA4452 to PA4456 and This study the FRT-Gm ${ }^{R}$-FRT cassette cloned into EcoRI/BamHI sites of pEX100T-KS, $\mathrm{Cb}^{\mathrm{R}}, \mathrm{Gm}^{\mathrm{R}}$

\section{OLIGONUCLEOTIDES}

AD2

5'-CANGCTWSGTNTSCAA

GM447

5'-GTGCAAGCAGATTACGGTGACGAT

GM464

Pr4455/Xh5'

5'-TGACGATCCCGCAGTGGCTCTC

Pr4455/Bm3'

\section{CCGCTCGAGCGAATGTGGCGCCTGGAT}

CGGGATCCCATCAGGACTCCTTGCGATGC

PA4455/Eco5'

GGAATTCATGACTGGGAGAGCGCTGATGCGTAGAGTCTCTCCCCTC

CGGGATCCTCAGAAATCTCCAAACATCAAAGC

$\mathrm{PA} 4455 / \mathrm{Bm}^{\prime}$

\section{CCTGTTGCTGGCCTTCATA}

CTGCTGACCTTGGCAATCT

AACGCGCTGCTCGAATA

CTGTCACGGATCTCCATGTT

GACCATGGAGATCAACCAGAAC

GACGCTGATGCCGATGTATT

ATGAAGGCCACCGAACAG

CAGCGGCATGGAGATGAA

TCACCGATCTCGACGTCTT

GAAGCTTCATCAGGACGATGT

AGGAAGAAGAAGTCACCAACAG

TCCTCTTCCAGAGCCATCA
Arai et al., 1995

Arai et al., 1995

Arai et al., 1995

This study

This study

Caetano-Anolles, 1993

Caetano-Anolles, 1993

Caetano-Anolles, 1993

This study

This study

This study

This study

PA4456 REV

acpP FWD

acpP REV

This study

This study

This study

This study

This study

This study

This study

This study

This study

This study

This study

This study

$A p^{R}$, ampicillin resistant; $C b^{R}$, carbenicillin resistant; $T C^{R}$, tetracycline resistant; $G m^{R}$, gentamycin resistant. 


\section{Construction of $P A$ Mutants}

\section{Transposon (Tn) Mutagenesis}

Wild-type strain PAO1 was subjected to transposon mutagenesis using the mariner transposon vector, pBT20 (Kulasekara et al., 2005). The transposon within pBT20 was conjugally transferred by biparental mating using E. coli S17-1 $\lambda$ pir into strain PAO1 following a protocol described elsewhere (Kulasekara et al., 2005). Mating mixtures were scraped and resuspended in $1 \mathrm{ml}$ of L-broth. Suspensions $(300 \mu \mathrm{l})$ were spread evenly onto Pseudomonas isolation agar (PIA) plates containing gentamicin $(\mathrm{Gm})$ at $150 \mu \mathrm{g} / \mathrm{ml}$, and incubated at $37^{\circ} \mathrm{C}$ for $48 \mathrm{~h}$. Conjugants were picked and patched onto freshly prepared LBN plates, $\mathrm{pH} 6.5$ containing $15 \mathrm{mM} \mathrm{A}-\mathrm{NO}_{2}^{-}$and further incubated again at $37^{\circ} \mathrm{C}$ for $48 \mathrm{~h}$. A- $\mathrm{NO}_{2}^{-}$sensitive conjugants were selected, purified and confirmed for susceptibility to $\mathrm{A}-\mathrm{NO}_{2}^{-}$. Transposon insertion sites were determined through sequencing the flanking region of the transposon by a semi-random PCR method, as described previously (Caetano-Anolles, 1993) using random primer $\mathrm{AD} 2$ and transposon-specific primer Gm447, followed by the nested primers Gm464 and AD2 (Table 1).

\section{Allelic Exchange, Sucrose Counter-Selection}

The strategy for insertional inactivation of some of the genes, primarily PA4455 derivatives listed in Table 1 was facilitated by gene disruption with an 850-bp gentamicin resistance $\left(\mathrm{Gm}^{\mathrm{R}}\right)$ cassette from pUCGM (Schweizer, 1993). The gene replacement vector pEX100T (Schweizer, 1992) was used to allow for selection of double-crossover events within putative recombinants cultured on LB-agar medium containing $150 \mu \mathrm{g} / \mathrm{ml} \mathrm{Gm}$ and subsequently with $7 \%$ sucrose for counterselection. All mutants were confirmed by PCR and DNA sequencinxg analysis.

\section{qPCR Analysis of Wild-Type and Mutant Strains}

Strains PAO1, PA4455, and PA4455 complemented with pUCPPA4455 were grown overnight in LB media. The strains were then sub-cultured the next day into fresh LB and allowed to grow to late log phase. The bacteria were then harvested and subjected to RNA extraction using an RNeasy Protect Bacteria Mini Kit (Qiagen), including a DNase reaction to remove endogenous genomic DNA. Equal amounts of RNA were used in a Reverse Transcriptase Reaction (Im-Prom II Reverse Transcription System) to obtain total cDNA that was then used in a PCR reaction to confirm qualitatively the absence of the gene from the mutant strain. Subsequently, the same samples were used in a qPCR reaction using the StepOnePlus System (Thermo Scientific, Applied Biosystems). Amplification was detected using PowerUp SYBR Green Master Mix (Applied Biosystems). Primers directed against PA4452, PA4453, PA4454, PA4455, $P A 4456$ and a "housekeeping" gene, acpP, were developed using IDT primer design tools (Integrated DNA Technologies) to create $\sim 100$-bp fragments, so as to minimize errors between gene amplification measurements. Threshold cycle values were used to determine relative gene expression using the $\Delta \Delta \mathrm{C}_{\mathrm{T}}$ method (Livak and Schmittgen, 2001).

\section{SDS, EDTA, and $\mathrm{NaNO}_{2}$ Killing Studies}

Aerobically grown bacteria were serially diluted on square Petri dishes containing either $\mathrm{LB}$ or $\mathrm{LBN}$ agar, $\mathrm{pH} 6.5, \pm 7.5$ or $17 \mathrm{mM} \mathrm{A}-\mathrm{NO}_{2}^{-}, 0.5 \%$ SDS, or $1 \mathrm{mM}$ EDTA. Details of the strains used for these studies are provided in the figure legends. The diluted suspensions were spotted $(10 \mu \mathrm{l})$ on the surfaces of the plates and the organisms allowed to incubate at $37^{\circ} \mathrm{C}$ under aerobic or anaerobic conditions, the latter using a Coy Laboratory Anaerobic Chamber (Grass Lake, MI).

\section{P PA4455-lacZ Fusion and Complementary Plasmid Construction}

The $\mathrm{P}_{P A 4455}$ - lacZ transcriptional fusion was constructed by amplifying the PA4455 operon promoter region, encompassing nucleotides 810-1223 bp upstream of the start codon of PA4455. PCR was performed using primers Pr4455/Xh5' and Pr4455/Bm3' with PAO1 chromosomal DNA. The resulting 413bp fragment was excised with XhoI and BamHI, and ligated to a 3-kb BamHI/HindIII-digested lacZ fragment. The resultant fusion was then cloned between the XhoI and HindIII sites of mini-CTX1 to yield mini-CTX1-P $P_{P A 4455}-$ lacZ. Chromosomal integration of this mini-CTX1- $P_{P A 4455}-$ lac $Z$ fusion vector in $P A$, excision of unwanted plasmid sequences and verification of insertion at the chromosomal attB locus were performed as described previously (Hoang et al., 2000). For genetic complementation studies, the coding region of PA4455 was amplified from PAO1 chromosomal DNA using oligonucleotides PA4455/Eco5' and PA4455/Bm3'. The EcoRI/BamHI-digested PCR product was cloned into pUCP20 (Schweizer, 1991) that had been digested with the same enzymes. Competent cells of the PAO1 PA4455 mutant were prepared and electroporated with 50 ng of the plasmid, pUC-PA4455. Transformants were selected on PIA plates containing carbenicillin at $500 \mu \mathrm{g} / \mathrm{ml}$.

\section{lacZ Transcriptional Analysis of $P_{P A 4455-l a c Z}$ and PQF50 Derivative Containing Strains}

For $\mathrm{P}_{P A 4455}$ - lac $Z$, overnight cultures of PAO1 attB:: $\mathrm{P}_{P A 4455}-$ lac $Z$ were diluted $1 / 100$ into $50 \mathrm{ml}$ of fresh $\mathrm{LBN}$ pH 6.5 and grown to early log phase, after which the samples were aliquoted into test tubes containing the respective treatments. These were then incubated for $2 \mathrm{~h}$ aerobically with shaking or $2.5 \mathrm{~h}$ anaerobically, both at $37^{\circ} \mathrm{C}$. For pQF50 derivative strains, overnight aerobic cultures of the bacteria were inoculated $1 / 100$ into fresh LBN, and the cultures were incubated aerobically or anaerobically overnight. Analysis of the activation of lacZ was carried out using methods described by Miller using slight modifications (Miller, 1992; Su et al., 2014). Briefly, a 400- $\mu$ l suspension of bacteria (OD600 1.0) was transferred to a glass tube and mixed with $600 \mu \mathrm{l}$ of Z-buffer. Twenty $\mu \mathrm{l}$ of $0.1 \%$ SDS and $40 \mu \mathrm{l}$ of chloroform were then added to the samples and vortexed. The samples were then incubated in a $28^{\circ} \mathrm{C}$ water bath for 5 min, after which $200 \mu \mathrm{l}$ of an ortho-nitrophenyl- $\beta$-galactoside solution (ONPG, $4 \mathrm{mg} / \mathrm{ml}$ ) was added to each sample. After briefly vortexing a timer was started and the samples were returned to the $28^{\circ} \mathrm{C}$ water bath. Reactions were stopped by 
the addition of $500 \mu \mathrm{l}$ of a $1 \mathrm{M}$ sodium carbonate solution. The samples were then centrifuged and $1 \mathrm{ml}$ of the supernatant was analyzed spectrophotometrically at $420 \mathrm{~nm}$. Utilizing the $\mathrm{OD}_{600}$, reaction time, and $\mathrm{A}_{420}$, the Miller units of each sample were then calculated. Results were analyzed using SPSS software (IBM, version 23). For pQF50 variants, independent $T$-tests were used to determine significance between PAO1 and PA4455 for each plasmid. For $P_{P A 4455}-$ lac $Z$ assays, one-way ANOVA was utilized to determine the significant differences among the group.

\section{Confocal Laser Scanning Microscopic Analysis for Determination of A- $\mathrm{NO}_{2}^{-}$ Sensitivity of PA Biofilms}

Biofilms were grown in glass-bottomed culture dishes (MatTek, Ashland, MA) essentially as described by Yoon et al. (2002). Briefly, overnight cultures were grown in L-broth to stationary phase and diluted 1:100 into the culture dishes containing $3 \mathrm{ml}$ of LBN. Samples were incubated anaerobically at $37^{\circ} \mathrm{C}$ for $24 \mathrm{~h}$. Planktonic cells were removed by washing the wells twice with PBS and fresh L-broth- $50 \mathrm{mM}$ potassium phosphate, $\mathrm{pH} 6.5$ containing $15 \mathrm{mM} \mathrm{KNO}_{3}$ (control) or $15 \mathrm{mM} \mathrm{KNO}_{3}$ plus $15 \mathrm{mM}$ $\mathrm{NaNO}_{2}$. Cultures were incubated in an anaerobic chamber for 2 days at $37^{\circ} \mathrm{C}$. After removing the planktonic cells by two washes with PBS, biofilm bacteria were exposed to a cell viability stain (BacLight, Invitrogen) composed of SYTO 9 and propidium iodine. Biofilm images were obtained using an LSM 710 confocal microscope (Zeiss, Heidelberg, Germany). The excitation and emission wavelengths for green fluorescence were 488 and $500 \mathrm{~nm}$, while those for red fluorescence were 490 and $635 \mathrm{~nm}$, respectively. All biofilm experiments were repeated indepently at least 3 times. The live/dead ratios of the biofilms were calculated using the ImageJ software. The percentage of dead/live ratio was normalized after comparisons between treated $\left(\mathrm{NO}_{3}^{-}\right.$plus $\left.\mathrm{NO}_{2}^{-}\right)$ and control $\left(\mathrm{NO}_{3}^{-}\right.$alone).

\section{Antibiotic MIC Determinations}

Minimum inhibitory concentration (MIC) testing was performed using the Etest system (bioMerieux, Marcy-l-Etoile, France) following manufacturer guidelines. Testing was performed using $150 \mathrm{~mm}$ cation adjusted Mueller Hinton agar plates (BD Diagnostics, Sparks, MD) incubated at $35^{\circ} \mathrm{C}$ for $18-24 \mathrm{~h}$ in ambient air.

\section{Mouse Acute Pneumonia Infection Model}

Six-week old male BALB/c mice (19-21 g) were purchased from Taconics (Cambridge City, IN). All animals were housed in positively ventilated microisolator cages with automatic recirculating water located in a room with laminar, high efficiency particulate-filtered air. The animals received autoclaved food, water, and bedding. Mice were handled in accordance with approved protocols through the Institutional Animal Care and Use Committee at the University of Illinois at UrbanaChampaign. Mice were infected intranasally with $1 \times 10^{6} \mathrm{CFU}$ of strain PAO1, the PA4455 mutant, or the complemented strain (pUCP-PA4455; Zhang et al., 2005; Hao et al., 2011). After 20 h, mice were euthanized and lungs were harvested, homogenized, serially diluted and plated on PIA with or without $400 \mu \mathrm{g} / \mathrm{ml}$ carbenicillin for determination of bacterial load.

\section{Transmission Electron Microscopy (TEM) of Bacterial Samples}

Overnight cultures were diluted 1:100 in fresh L-broth and incubated at $37^{\circ} \mathrm{C}$ with shaking until late log phase. Culture samples were removed and adjusted to an $\mathrm{OD}_{600}$ of 1.0 and the bacteria clarified by centrifugation at $2600 \mathrm{RPM}\left(\sim 600 \times^{\mathrm{g}}\right)$ for $5 \mathrm{~min}$. The cells were then prepared for TEM using a protocol described by Kim et al. (2007) with slight modifications. The cells were washed three times in $0.1 \mathrm{M}$ sodium cacodylate, then stained and fixed with a 1:1 mixture of $1 \%$ osmium tetraoxide with $7.5 \mathrm{mg} / \mathrm{ml}$ of potassium ferricyanide and a $5 \%$ glutaraldehyde solution. After $1 \mathrm{~h}$, the cells were washed again with $0.1 \mathrm{M}$ sodium cacodylate and subjected to a graded series of ethanol (25-100\%), each for $15 \mathrm{~min}$, followed by a $100 \%$ acetone wash for another $15 \mathrm{~min}$. The cells were infiltrated and embedded in LX-112 Resin (Ladd Research Industries). The resin was sectioned using a Leica EM UC 7 ultramicrotome to $100 \mathrm{~nm}$. Images were taken on a Hitachi H 750 transmission electron microscope operating at $100 \mathrm{kV}$.

\section{RESULTS}

\section{Identification of PA4455, Encoding a Putative ABC Transporter Permease: A Gene Critical for Resistance to A- $\mathrm{NO}_{2}^{-}$}

In this study, we used a Tn mutagenesis approach to identify mutants that demonstrated increased sensitivity to A- $\mathrm{NO}_{2}^{-}$relative to wild-type bacteria. Colonies that were patched from PIA-Gm plates onto PIA-Gm/A-NO $\mathrm{NO}_{2}^{-}$plates that showed little or no growth were screened for $\mathrm{A}-\mathrm{NO}_{2}^{-}$ sensitivity followed by sequencing of the Tn-interrupted gene. The most sensitive mutant whose gene product was not deemed cytoplasmic in location based upon the membrane topology program SOSUI (http://harrier.nagahama-i-bio.ac.jp/ sosui/sosui_submit.html), and hence a potential viable drug target, was that involving a Tn insertion within the PA4455 gene. The PA4455 gene encodes a putative $\mathrm{ABC}$ transporter permease that has 6 predicted membrane-spanning domains (Figures 1A,B) within the cytoplasmic membrane (Class 3). However, experimental evidence also shows that the 28.4$\mathrm{kDa}$ protein encoded by PA4455 can also be localized within membrane vesicles (class I) based upon MALDI-TOF mass spectrometric analysis (www.pseudomonas.com; Choi et al., 2011). This predicted topology was also supported by other cellular localization programs including TOPPRED (https:// bioweb.pasteur.fr/packages/pack@toppred@1.10) and PSORTb V. 3.0 (http://www.psort.org/psortb/; data not shown).

The initial transponson mutant (designated P33) had a Tn insertion located $436 \mathrm{bp}$ from the $5^{\prime}$ end of the PA4455 ORF with $\mathrm{Gm}$ resistance determinant (aaC1) transcribed in the same orientation as PA4455 (Figure 2). We believed it was unlikely that the $\mathrm{Tn}$ insertion would exert any polar effects on downstream genes that included PA4454, PA4453, 


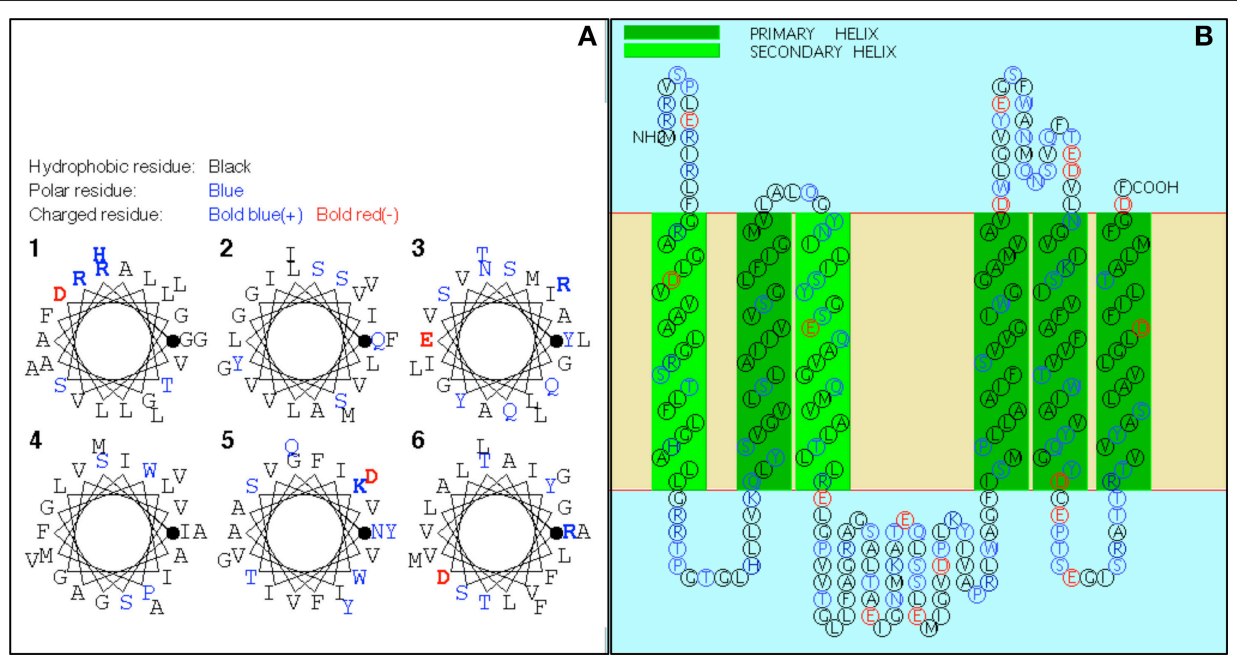

FIGURE 1 | Software predictions of the transmembrane domains of PA4455. (A) Helical wheel diagram of predicted transmembrane segments of PA4455. Hydrophobic residues, black; Polar residues, blue; Charged residues, Bold blue (+) and Bold red (-). (B) Predicted membrane topology of PA4455 within the cytoplasmic membrane. Primary and secondary membrane spanning helices are indicated by dark or light green color, respectively.

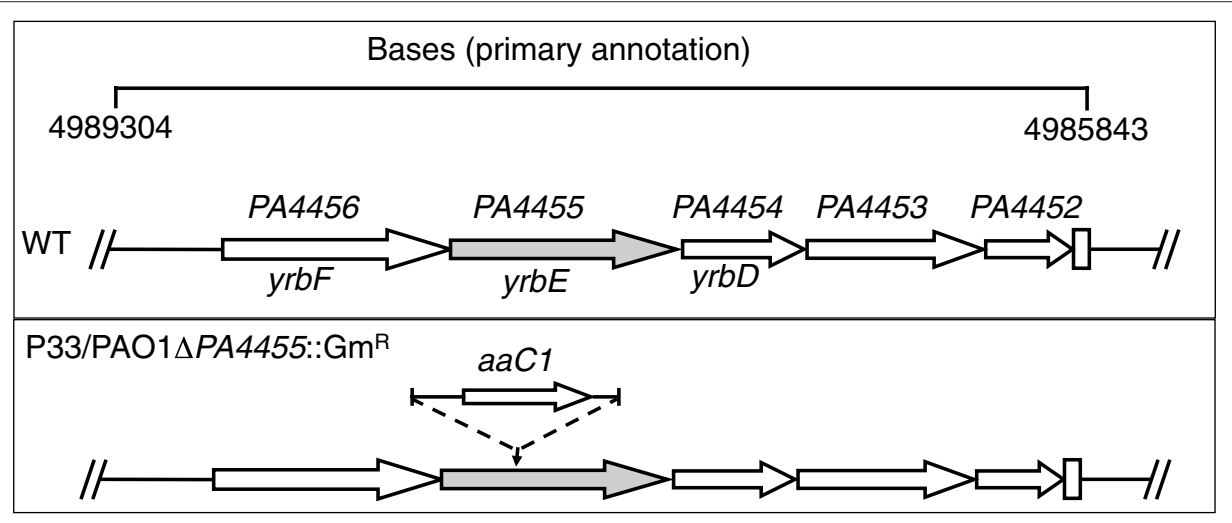

FIGURE 2 | Schematic diagram of the strategy to generate a deletion mutant of the PA4455 gene. The genomic region of $P A$ spanning base pairs 4989304-4985843 are shown at the top of the figure. The designated genes yrbF, yrbE, and yrbD are based upon homology to Bacillus subtilis genes as analyzed by www.pseudomonas.com. The second construct, PAO1 PA4455::GmR ${ }^{R}$, harbors a gentamicin resistance cassette (GmR ${ }^{R}$ interrupting the PA4455 gene.

and PA4452, each of which encode conserved hypothetical proteins, respectively. We next constructed a PA4455 knockout mutant using the standard strategy of insertional disruption with a gentamycin cassette $\left(\mathrm{Gm}^{\mathrm{R}}\right)$ followed by allelic exchange (Figure 2). The resultant mutant strain, PAO1 PA4455::Gm $\mathrm{G}^{\mathrm{R}}$, exhibited the same level of sensitivity to $A-\mathrm{NO}_{2}^{-}$as the Tn mutant P33. We did not believe this mutant would have any polar effects on nearby genes. Although modest increases in mRNA levels of up- and down-stream genes were observed in the mutants, we do not believe this is causing the phenotypic effects observed in this work because of the complementation of each phenotype by provision of PA4455 in trans. This was confirmed by transcriptional analysis of the aforementioned genes using qPCR, comparing the gene expression to a previously used housekeeping gene acpP (Supplementary Figure 1) from both aerobically and anaerobically grown samples (Lenz et al., 2008). Both mutant strains displayed no growth defect in regular
LB or LBN media compared to the wild-type strain PAO1 (data not shown). Thus, we used PAO1-PA4455::Gm ${ }^{\mathrm{R}}$ (herein PA4455 mutant) for the remainder of our studies.

\section{Sensitivity of Planktonic PA4455 Mutant Bacteria to A- $\mathrm{NO}_{2}^{-}$under Aerobic and Anaerobic Conditions}

Using a simple serial dilution plating assay, we monitored the sensitivity of the PA4455 mutant bacteria relative to wild-type bacteria and complemented strains. Serially diluted bacterial suspensions were spotted onto LBN plates $\pm 17 \mathrm{mM} \mathrm{A-NO}-$ (aerobic) or $7.5 \mathrm{mM} \mathrm{A}-\mathrm{NO}_{2}^{-}$(anaerobic), respectively, based on preliminary experiments which determined these concentrations as a minimum to discern a noticeable effect on viability (data not shown). The results in Figure 3B (compared to Figure 3A controls) demonstrates that the PA4455 mutant is dramatically 


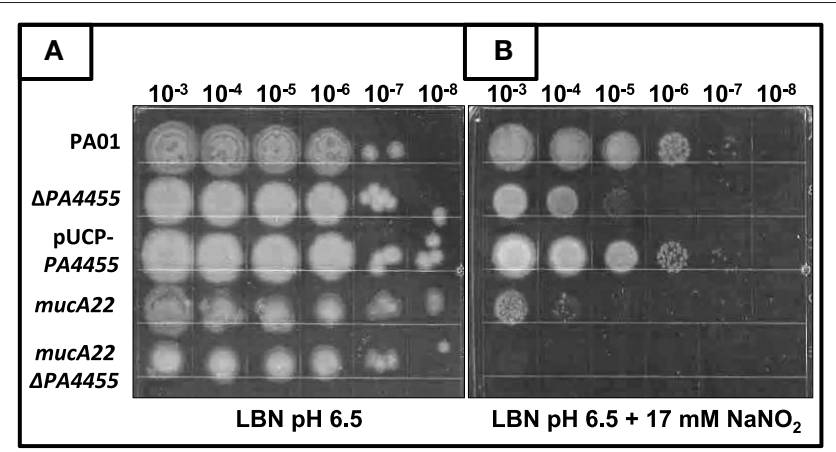

FIGURE 3 | Sensitivity of planktonic PA4455 mutant bacteria to A-NOunder aerobic conditions. Serial dilutions ( $\mathrm{X}$-axis) of aerobically grown stationary phase bacteria were spotted onto LBN plates (A, control) or (B) LBN plates $\pm 17 \mathrm{mM} \mathrm{A}-\mathrm{NO}_{2}^{-}$and incubated aerobically for $48 \mathrm{~h}$ at $37^{\circ} \mathrm{C}$. The lids were removed and the plates were scanned by an HP Scanjet $7400 \mathrm{c}$ using Adobe Photoshop and edited for visual clarity using Powerpoint:Mac2011 software.

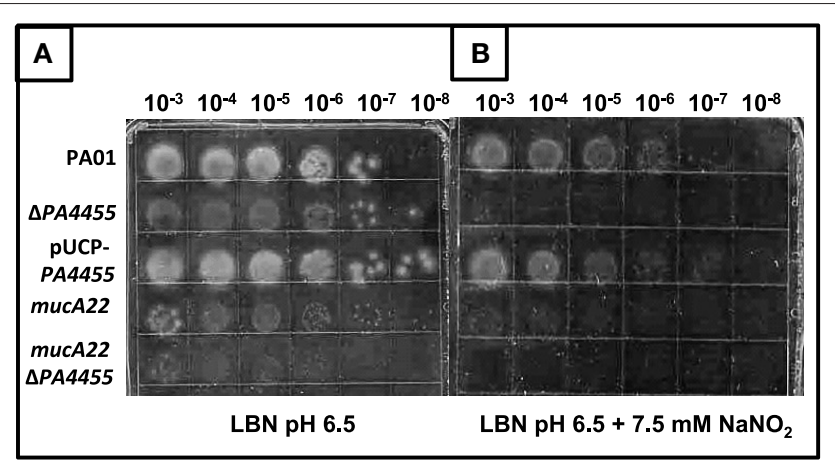

FIGURE 4 | Sensitivity of planktonic PA4455 mutant bacteria to A-NO under anaerobic conditions. Serial dilutions ( $\mathrm{X}$-axis) of aerobically grown stationary phase bacteria were spotted onto LBN plates (A, control) or $\mathbf{( B )} \pm$ $7.5 \mathrm{mM} \mathrm{A}-\mathrm{NO}_{2}^{-}$and incubated anaerobically for $48-72 \mathrm{~h}$ at $37^{\circ} \mathrm{C}$. The lids were removed and the plates were scanned by an HP Scanjet 7400c using Adobe Photoshop and edited for visual clarity using Powerpoint:Mac2011 software.

more sensitive to $\mathrm{A}-\mathrm{NO}_{2}^{-}$than wild-type bacteria under both aerobic and, most dramatically, under anaerobic conditions (Figure 4B compared to Figure 4A). Complementation was achieved in trans on a multi-copy plasmid, pUCP-PA4455. For comparison, we also used mucoid mucA22 (previously shown to be sensitive to $\mathrm{A}-\mathrm{NO}_{2}^{-}$Yoon et al., 2006) and a mucA22 PA4455 double mutant. Interestingly, both mucA22 and the double mutant bacteria were indistinguishable in anaerobic A$\mathrm{NO}_{2}^{-}$sensitivity relative to the PA4455 mutant alone (Figure 4B) yet the double mutant was $\sim 10$-fold more sensitive to $\mathrm{A}-\mathrm{NO}_{2}^{-}$ under aerobic conditions (Figure 3B).

\section{Sensitivity of Biofilm PA4455 Mutant Bacteria to $\mathrm{A}-\mathrm{NO}_{2}^{-}$under Anaerobic Conditions}

Since $\mathrm{A}-\mathrm{NO}_{2}^{-}$sensitivity in $P A$ is more pronounced under anaerobic conditions (Yoon et al., 2006), we next elected to grow bacteria as a biofilm under anaerobic conditions via $\mathrm{NO}_{3}^{-}$ respiration and assess the relative sensitivity of wild-type and the PA4455 mutant to $\mathrm{A}-\mathrm{NO}_{2}^{-}$. We have previously shown that anaerobic conditions favor more robust biofilm formation than under aerobic conditions (Yoon et al., 2002). In this experiment, we observed that the PA4455 mutant is highly sensitive to A$\mathrm{NO}_{2}^{-}$when compared to wild-type and complemented bacteria, as shown by a shift in the live/dead ratio of the biofilm bacteria (Figures 5A,B).

\section{Denitrification Pathway Transcriptional Activities are Increased under Anaerobic Conditions in the PA4455 Mutant Relative to Wild-Type Bacteria}

To evaluate whether transcription of genes involved in anaerobic respiration were potentially altered in the PA4455 mutant relative to wild-type bacteria that may alter the overall sensitivity to A$\mathrm{NO}_{2}^{-}$of the PA4455 mutant observed in Figures 3B, 4B, we assessed the aerobic and anaerobic transcriptional activity of the nirS (encoding nitrite reductase), nirQ (encoding the NirQ anaerobic regulator), norC (encoding the NorC component of NO reductase) and narK (encoding the NarK efflux pump) promoters using classical lac $Z$ fusion analyses. $P A$ strains PAO1 (wild-type) and its isogenic PA4455 mutant were transformed with pQF50 (vector control), pHA531 (nirS::lacZ), pHA532 (nirQ::lacZ), pHA533 (norC::lacZ), or pQF-narK (narK::lacZ), respectively. Next, $\beta$-galactosidase activity was measured in cells grown in LBN broth under aerobic and anaerobic conditions overnight. In support of our hypothesis, the PA4455 mutant exhibited a clear upregulation of several of the aforementioned genes anaerobically, indicating that $\mathrm{NO}_{3}^{-}$may more readily pass through the membrane of the mutant and trigger transcriptional activation of these genes. This presumably could apply to $\mathrm{NO}_{2}^{-}$ as well, explaining the increased sensitivity to it. Under aerobic conditions, transcriptional activity was noticeably lower in strain PA4455 when compared to wild-type levels, which, although unexpected, indicate that perhaps the cell has developed an altered preference for the available nitrogen sources (Figure 6A). Anaerobically, when the denitrification pathway is active, gene activation levels increased dramatically (often $\sim 2$-fold higher) in the PA4455 mutant relative to the wild-type in nirS, and nor $C$ transcription, but interestingly not in narK transcription (Figure 6B). Unexpectedly, nirQ was lower anaerobically in PA4455 than in PAO1, although both levels were also lower than their respective controls.

\section{Response of the PA4455 Mutant to Membrane Stressors: Sensitivity to the Chelator EDTA but Not SDS}

SDS has been shown more than 40 years ago to cause significant bacterial membrane damage with subsequent release of DNA, RNA and protein (Woldringh and van Iterson, 1972). It has also long been known that the chelator EDTA has pleotropic effects on the lipopolysaccharide of PA (Champlin et al., 2005; Alakomi et al., 2006). Thus, we postulated that the PA4455 mutant, because of an absence of the 6 membrane-spanning 


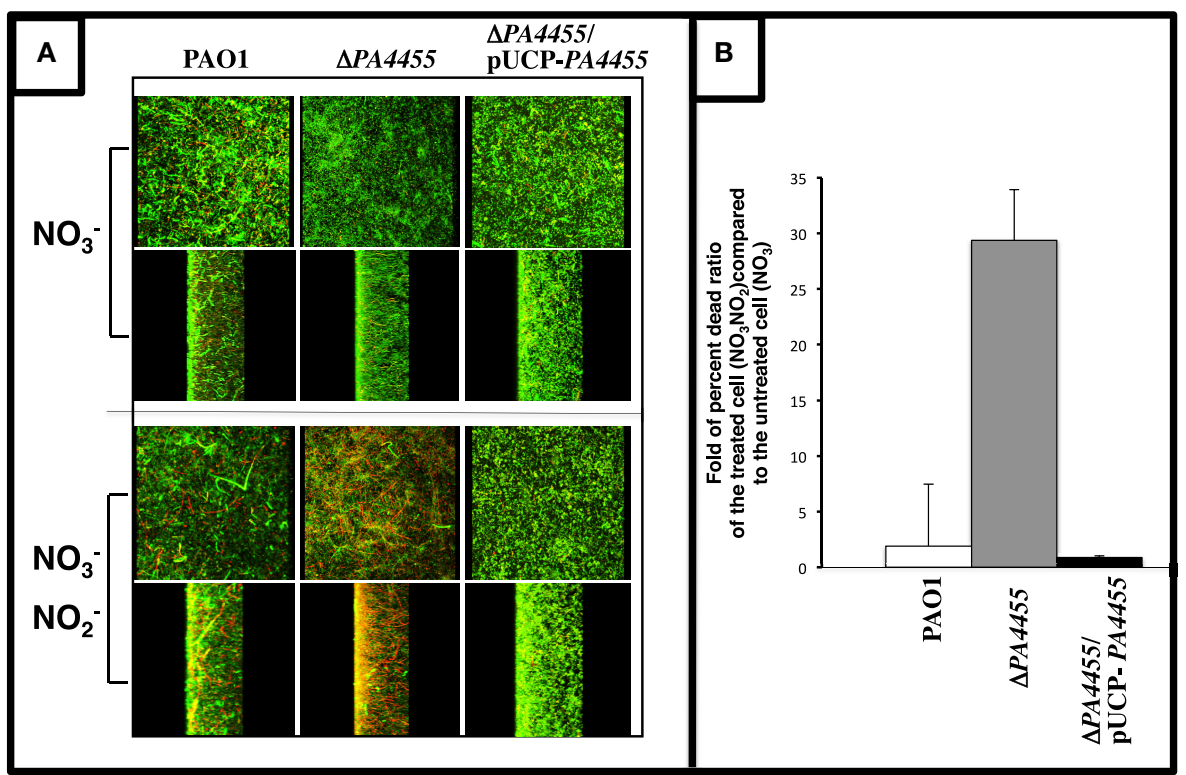

FIGURE 5 | Sensitivity of biofilm PA4455 mutant bacteria to A-NO- under anaerobic conditions. (A) Biofilms were grown anaerobically in LBN for $24 \mathrm{~h}$ in glass bottomed culture dishes. Spent medium was gently aspirated and replaced with $\mathrm{LBN}-50 \mathrm{mM}$ potassium phosphate, $\mathrm{pH} 6.5$, containing $15 \mathrm{mM} \mathrm{NaNO}_{2}$. Cultures were incubated in an anaerobic chamber for 2 days at $37^{\circ} \mathrm{C}$. Biofilms were then stained a cell viability stain (BacLight, InVitrogen) composed of SYTO 9 and propidium iodine. Biofilm images were obtained using an LSM 510 confocal microscope (Carl Zeiss, Inc., Germany). The excitation and emission wavelengths for green fluorescence were $488 \mathrm{~nm}$ and $500 \mathrm{~nm}$, while those for red fluorescence were $490 \mathrm{~nm}$ and $635 \mathrm{~nm}$, respectively. All biofilm experiments were repeated at least 3 times. (B) The live/dead ratios of the biofilms were calculated using ImageJ image processing program.

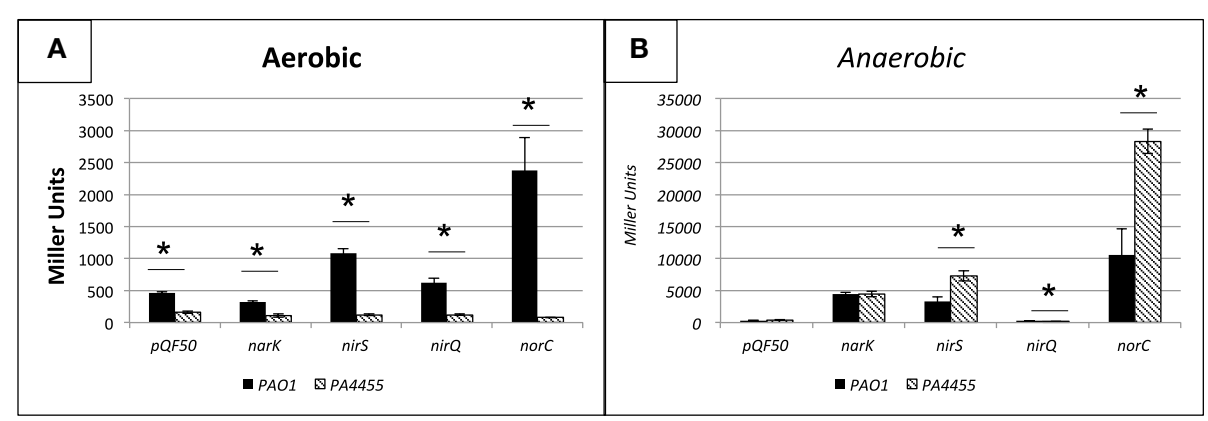

FIGURE 6 | Transcriptional activity of the nirS, nirQ, norC, and narK promoters probed by lacZ fusion analysis under aerobic (A) versus anaerobic (B) conditions. PA PAO1 (wild-type) and its isogenic $\triangle P A 4455:: G m^{R}$ mutant were transformed with pQF50 (vector control), pHA531 (nirS::lacZ), pHA532 (nirQ::lacZ), pHA533 (norC::lacZ), or pQF-narK (narK::lacZ), respectively. $\beta$-galactosidase activity was measured in cells grown in LBN broth under aerobic and anaerobic conditions. Reported values are the averages of 4 independent experiments. ${ }^{*}$ ) designates $>95 \%$ confidence.

protein, $P A 4455$, may be unusually sensitive to not only A$\mathrm{NO}_{2}^{-}$(Figures 3-5) but also to EDTA and SDS. In addition, its homolog in E. coli demonstrated sensitivity to EDTA and several other membrane stressors, suggesting that perhaps this phenomenon would exist in $P A$ as well (Malinverni and Silhavy, 2009). The results displayed in Figure 7B clearly indicate that the wild-type and all tested mutant and complemented bacteria were not sensitive to $0.5 \%$ SDS relative to control bacteria (Figure 7A). In contrast, treatment of bacteria with $1 \mathrm{mM}$ EDTA clearly killed the vast majority of the PA4455 mutant bacteria (Figure 7C). We also tested alginate-overproducing strains $P A$ mucA22, which expresses a truncated $15.8-\mathrm{kDa}$ MucA protein, and a $m u c A$ deletion mutant $(\triangle m u c A)$. Surprisingly, only the $\triangle m u c A$ strain was sensitive to $1 \mathrm{mM}$ EDTA.

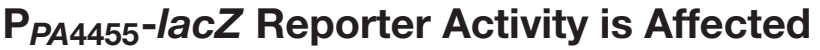 by Treatment with EDTA but Not A-NO- SDS or Polymyxin B}

We next elected to assess whether $\mathrm{A}-\mathrm{NO}_{2}^{-}$, EDTA, SDS, or polymyxin $\mathrm{B}(\mathrm{PMB})$ affected transcription of the PA4455 gene. Wild-type bacteria were transformed with a miniCTX-pPA4455-lacZ reporter plasmid for attB integration. For $\mathrm{p} P A 4455$, it was found that reporter activity was increased in response only to EDTA, but interestingly not to any of 


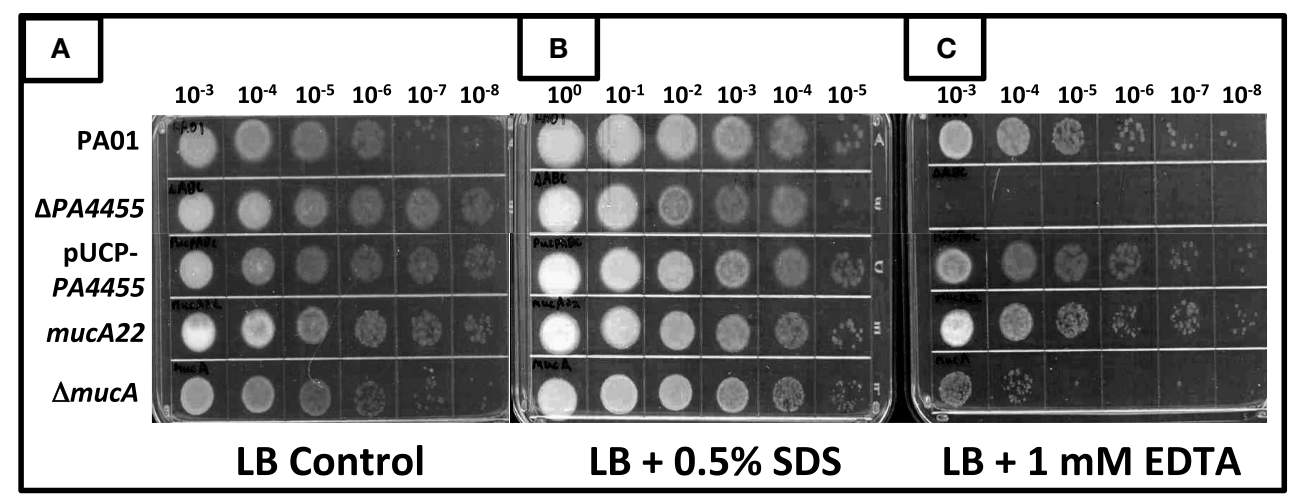

FIGURE 7 | Sensitivity of various mutant strains to the membrane permeabilizing agents SDS and EDTA. Serial dilutions (X-axis) of aerobically grown stationary phase bacteria were spotted onto LBN plates (A), control, (B) $0.5 \%$ SDS, or (C) $1 \mathrm{mM}$ EDTA and incubated aerobically for $48 \mathrm{~h}$ at $37^{\circ} \mathrm{C}$. The lids were removed and the plates were scanned by an HP Scanjet 7400c using Adobe Photoshop and edited for visual clarity using Powerpoint:Mac2011 software.

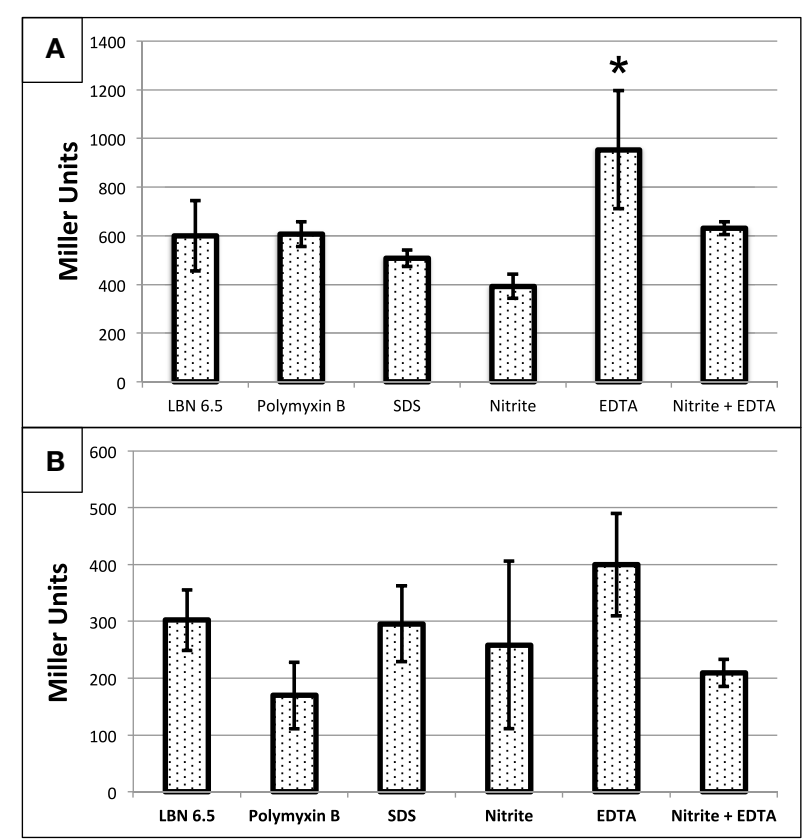

FIGURE 8 | Transcriptional activity of PA4455 in response to different stressors under (A) aerobic or (B) anaerobic conditions. PAO1 attB::pPA4455-lacZ was used to determine the activation of PA4455 under membrane stress. Cells were incubated aerobically (A) or anaerobically (B) overnight with the different stresses $\left(10 \mathrm{mM} \mathrm{NaNO}_{2}, 0.5 \mathrm{mM}\right.$ EDTA, $0.5 \%$ SDS, or $2 \mu \mathrm{g} / \mathrm{ml}$ of polymyxin B). Then, the samples were diluted to an O.D.600 of approximately 0.4 and $\beta$-galactosidase activity was measured. Reported values are the average of 3 independent experiments. $\left(^{*}\right)$ designates $>90 \%$ confidence.

the other agents (Figure 8). This suggests that the protein is at least partially responsible for structural stability (or the response to repair) of the cell membrane. The most dramatic response was due to EDTA, which caused a $\sim 1.6$-fold increase in reporter activity. Statistical significance only existed for EDTA aerobically $(p<0.05$ against all groups except the combination treatment) but not anaerobically using a one-way ANOVA.

\section{B-band but Not A-band}

\section{Lipopolysaccharide (LPS) O-antigen} Mutants are Defective in Anaerobic Growth and are More Susceptible to the Effects of A-NO ${ }_{2}^{-}$and EDTA

We next postulated that one cellular structure that might be affected by the combined microbicidal activities of $\mathrm{A}-\mathrm{NO}_{2}^{-}$ and/or EDTA would be the LPS of PA. EDTA is notorious for damaging the outer membrane of Gram-negative bacteria such as PA (Alakomi et al., 2006). With such damage, LPS molecules with associated proteins have been shown to be released into the medium (Matsushita et al., 1978), further compromising the outer membrane function that can lead to cell death. One function of LPS, the major component of the outer membrane, is to help protect the membrane from potential damaging agents. We postulated that an absence of the putative $A B C$ transporter permease, $P A 4455$, could perturb the inner membrane of $P A$, that may, in turn, affect the overall behavior of the outer membrane and associated LPS molecules. Given that lipid A mutants cannot be constructed because such mutations are lethal, we used Oantigen (A-band- and/or B-band-deficient) mutants of the LPS layer and assessed the antimicrobial activity of $\mathrm{A}-\mathrm{NO}_{2}^{-} \pm$EDTA in comparison to sensitivity of wild-type bacteria. These mutants included $r m l C\left(\mathrm{~A}^{-} \mathrm{B}^{-}\right.$, encoding a $\mathrm{C}^{\prime}$ and $\mathrm{C}^{\prime}$ carbohydrate epimerase Rahim et al., 2000; Dong et al., 2007), rmd ( $\mathrm{A}^{-} \mathrm{B}^{+}$, that converts GDP-D-mannose to GDP-D-rhamnose (Rocchetta et al., 1998b), and $w b p M\left(\mathrm{~A}^{+} \mathrm{B}^{-}\right.$; Creuzenet and Lam, 2001), respectively (Supplementary Figure 2, Figure 9). Our results revealed that an $r m d$ mutant was the least affected when growing anaerobically or in the presence of either $15 \mathrm{mM} \mathrm{NO}_{2}^{-} \pm 1 \mathrm{mM}$ EDTA (Figure 9). However, consistent with a previous report (Murphy et al., 2014), the rmd mutant grew more efficiently than wild-type bacteria under both aerobic and anaerobic conditions. In contrast, mutants that do not produce B-band LPS, wbpM, and most pronounced in $\mathrm{rmlC}$, either grow extremely poorly or do not grow under anaerobic conditions. The $r m l C$ mutant, however, was the most susceptible when grown in the presence of either $15 \mathrm{mM} \mathrm{NO}_{2}^{-}$or $1 \mathrm{mM}$ EDTA. These observations suggest 

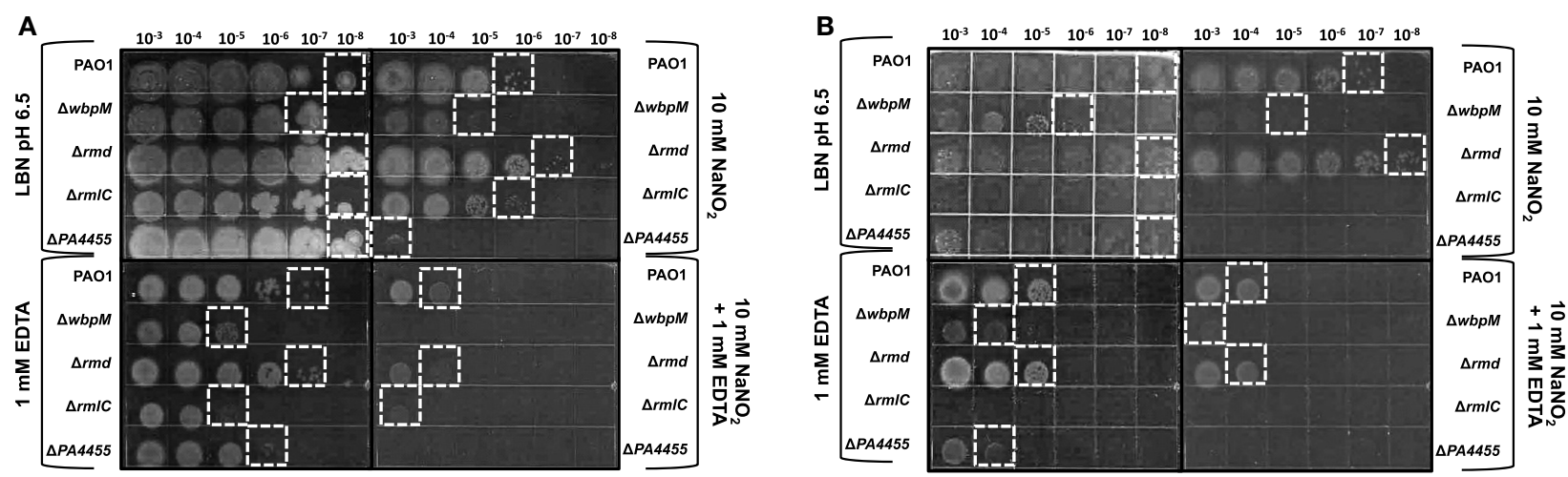

FIGURE 9 | Susceptibility of planktonic LPS mutants vs. PA4455 to A-NO- and EDTA under aerobic vs. anaerobic conditions. PAO1 (A+, B+), wbpM $(\mathrm{A}+, \mathrm{B}-)$, rmd $(\mathrm{A}-, \mathrm{B}+)$, and $r \mathrm{~m} / \mathrm{C}(\mathrm{A}-, \mathrm{B}-)$ were grown aerobically overnight at $37^{\circ} \mathrm{C}$ in $\mathrm{LB}$, and then sub-cultured into $\mathrm{LBN}$ pH 6.5 media at a $1: 100$ ratio. Serial dilutions were spotted on LBN plates containing control $50 \mathrm{mM}$ potassium phosphate, $\mathrm{pH}$ 6.5, $\pm 10 \mathrm{mM} \mathrm{NaNO}_{2}, \pm 1$ mM EDTA and incubated aerobically $(\mathbf{A}, 24-48$ h) or anaerobically $(\mathbf{B}, 72 \mathrm{~h})$ at $37^{\circ} \mathrm{C}$. The hatched white boxes designate where noticeable growth occurred on the plates.

that B-band LPS is required to shield the PA outer membrane from the bactericidal effects of EDTA and A-NO 2 , yet also is essential for optimal anaerobic growth and survival (Figure 9).

\section{Antibiotic MIC Determinations}

Since the $P A 4455$ protein is predicted to facilitate transport of small molecules into $P A$, we next assessed whether the $P A 4455$ mutant possessed altered minimal inhibitory concentration (MIC) values to a large panel of antibiotics. The PA4455 mutant was 4-, 6-, 8-, and 8-fold more sensitive than wildtype bacteria to chloramphenicol, colistin, tigecycline, and doxycycline, respectively (Table 2). In contrast, the mutant strain was 4 - and 64-fold more resistant to ticarcillin/clavulanic acid and gentamicin (serving as the positive resistance control), respectively.

\section{Attenuated Virulence of a PA4455 Mutant Relative to Wild-Type Bacteria}

Finally, we assessed the role of PA4455 in animal virulence using an established acute murine lung infection model of $P A$ infection. Mice were infected intranasally as we have previously described (Lau et al., 2005) using $1 \times 10^{6} \mathrm{CFU}$ of the wild-type, the PA4455 mutant, and PA4455-pUCP-PA4455 bacteria and the lungs harvested and homogenized after $20 \mathrm{~h}$. The $P A 4455$ mutant was found to be $\sim 10$-fold less virulent than wild-type bacteria (Figure 10).

\section{DISCUSSION}

\section{Microaerobic/Anaerobic Bacterial Biofilms in CF Airway Disease}

This study stemmed from two seminal works in 2002 demonstrating that $P A$ grows as microaerobic or anaerobic biofilms in thick mucus plugs lining the CF airway lumen (Worlitzsch et al., 2002; Yoon et al., 2002) and likely that of the COPD airway mucus (Hassett et al., 2014). Although initially the aforementioned studies were met with some skepticism (Alvarez-Ortega and Harwood, 2007), there

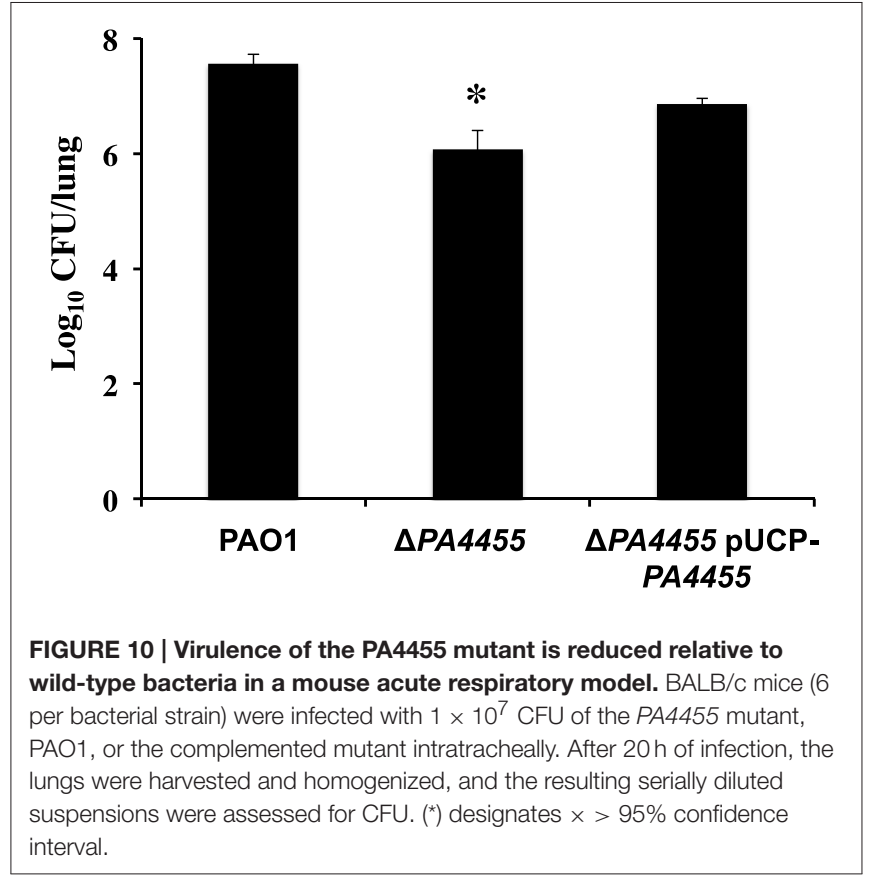

have been 205 citations in PUBMED when the words "anaerobic" and "cystic fibrosis" were searched prior to the submission of this work for publication (February 5, 2016). The definitive supporting work was provided by a research group (Tunney et al., 2008) who reported the isolation of obligate anaerobes in CF sputum. Furthermore, $P A$ infected sputum samples produce a gaseous product of anaerobic respiration nitrous oxide $\left(\mathrm{N}_{2} \mathrm{O}\right)$, further evidence that $P A$ is undergoing this process in the CF airway soccerball-shaped biofilms (Kolpen et al., 2014).

\section{A-NO- : Relevant Genes Involved in Resistance and Translational Potential}

Relatedly, one hallmark of both chronic CF and COPD is the emergence of the mucoid, mucA22 form of $P A$ that 
TABLE 2 | MIC's in $\mu \mathrm{g} / \mathrm{ml}$ for select antimicrobial agents representing different classes of antibiotics.

\begin{tabular}{|c|c|c|c|c|}
\hline Antimicrobial & PA01 & PA4455 & PA4455/pUCP-PA4455 & $\begin{array}{c}\text { Fold resistance (R) } \\
\text { or susceptible (S) }\end{array}$ \\
\hline Cefoxitin & $>256$ & $>256$ & $>256$ & No difference \\
\hline Ceftazadime & 2 & 2 & 2 & No difference \\
\hline Cefepime & 1.5 & 1.5 & 1.5 & No difference \\
\hline $\begin{array}{l}\text { Ticarcillin/ } \\
\text { Clavulanic Acid }\end{array}$ & 32 & 128 & 96 & $4^{\mathrm{R}}$ \\
\hline $\begin{array}{l}\text { Pipercillin/ } \\
\text { Tazobactam }\end{array}$ & 3 & 4 & 4 & No difference \\
\hline Imipenem & 2 & 2 & 2 & No difference \\
\hline Meropenem & 1 & 1.5 & 1 & No difference \\
\hline Aztreonam & 2 & 3 & 4 & No difference \\
\hline Amikacin & 4 & 4 & 4 & No difference \\
\hline Gentamicin & 3 & 192 & 128 & $64^{R}$ \\
\hline Ciprofloxacin & 0.19 & 0.064 & 0.19 & \\
\hline Doxycycline & 32 & 4 & 16 & $8^{S}$ \\
\hline Tigecycline & 24 & 3 & 16 & $8^{S}$ \\
\hline Colistin & 3 & 0.5 & 2 & $6^{S}$ \\
\hline Chloramphenicol & 24 & 6 & 16 & $4^{S}$ \\
\hline
\end{tabular}

are highly resistant to conventional antibiotics used to treat the aforementioned diseases. Surprisingly, Hassett (1996) has previously shown that anaerobic conditions promote mucoid stability, while static aerobic growth allows for mucoid-tononmucoid conversion. In 2006, we demonstrated that mucoid mucA22 bacteria are surprisingly and uniquely susceptible to the NO-donor, $\mathrm{A}_{-} \mathrm{NO}_{2}^{-}$at $\mathrm{pH} 6.5$, the approximate $\mathrm{pH}$ of the CF airway mucus (Coakley et al., 2003; Yoon et al., 2006). Specifically, we demonstrated that $\mathrm{A}-\mathrm{NO}_{2}^{-}$killed mucoid $P A$ in (a) anaerobic biofilms; (b) sterile ultrasupernatants of airway secretions derived from explanted CF lungs; and (c) a mouse model of PA lung infection in a $\mathrm{pH}$-dependent fashion, with no organisms remaining after daily exposure to $\mathrm{A}-\mathrm{NO}_{2}^{-}$for 16 days (Yoon et al., 2006). The A- $\mathrm{NO}_{2}^{-}$translational approach for the treatment of mucoid $P A$ is also effective at killing methicillinresistant $S$. aureus (MRSA) and Burkholderia cepacia, that, with $P A$, represent two other major CF pathogens (Major et al., 2010). Finally, Yoon et al. (2006) clearly showed that A-NOat concentrations up to $300 \mathrm{mM}$ did not elicit $\mathrm{LDH}$ release from human CF airway epithelia or alter transepithelial short circuit current, transepithelial water flux, or IL-8 release. More recent comparable results to the aforementioned were also found independently by another research group (Zemke et al., 2014).

The seemingly paltry level of $\mathrm{NO}$ derived from $\mathrm{NO}_{2}^{-}$reduction also was found to trigger dispersion of mature, preformed biofilms (Barraud et al., 2006), likely an event that threatens bacterial viability within biofilms. Bacteria such as $P A$ possess an obvious protective mechanism against NO, the respiratory NO reductase (NOR). Thus, without NOR, the bacteria grow abysmally slowly under anaerobic conditions due to high endogenous NO production ( $\sim 16 \mu \mathrm{M}$; Yoon et al., 2007). Similar to the NO detoxifying properties of NOR, much to our surprise, we also recently discovered that the major catalase of $P A$, KatA, is produced at higher levels during anaerobic growth and is essential for optimal protection against endogenous $\mathrm{NO}$ and A- $\mathrm{NO}_{2}^{-}$treatment in both planktonic and biofilm culture due to its ability to "buffer" NO (Su et al., 2014). Many studies in both Gram-positive and Gram-negative bacteria have clearly shown that many $\mathrm{ABC}$ transporters are involved in resistance to a variety of antibiotics (Reilman et al., 2014; Pletzer et al., 2015). In one particular study, overexpression in a highly antibiotic-sensitive strain of $E$. coli of SmrA, a novel multidrug efflux pump from Stenotrophomonas maltophilia, allowed for resistance to fluoroquinolones, tetracycline, doxorubicin and multiple dyes (Al-Hamad et al., 2009). Our work shows that PA4455 is essential for optimal resistance to doxycycline (alters membrane permeability), tigecycline (alters membrane permeability), colistin (punctures cytoplasmic membrane), and chloramphenicol (transport via facilitated diffusion; Table 2). A study performed with $E$. coli revealed that an ABC transporter was essential for proper transport of lipopolysaccharide to the outer membrane (Sherman et al., 2013). Our results suggest that one of the functions of PA4455 is to stabilize the cytoplasmic membrane as well as to control the rate of A- $\mathrm{NO}_{2}^{-}$transport into $P A$ during anaerobic growth. As observed with the activation of the promoter-lac $Z$ fusion, the PA4455 mutant consistently expressed higher levels of some of the genes associated with the denitrification (anaerobic respiratory) pathway. While this in itself might suggest that the membrane would have significant alterations that could allow for greater access to nitrate or nitrite, none were immediately apparent by TEM (Supplementary Figure 3). Were such alterations to be present, they may be subtle and not easily detectable as clear physical membrane deformities, but rather structural changes or reorganizations due to a less stabilized membrane.

\section{EDTA is Synergistic with A-NO $\mathrm{NO}_{2}^{-}$in the Killing of $P A$}

EDTA has been shown to have markedly detrimental effects on bacterial outer membranes, ultimately causing leakage of LPS and increased permeabilization to biocides (Alakomi et al., 2006). In 1980, Wood et al. (1980) demonstrated the synergistic effect of EDTA and several antibiotics including penicillin G, ampicillin, tetracycline, gentamicin, and carbenicillin on mucoid and nonmucoid PA. EDTA has also been shown to inhibit $P A$ biofilm formation, especially under anaerobic conditions (O’May et al., 2009). Supportively, a recent study has shown that $\mathrm{A}-\mathrm{NO}_{2}^{-}$inhibited $99 \%$ of $P A$ biofilm formation on primary CF epithelial cell (Zemke et al., 2014). The same group also showed that $\mathrm{A}-\mathrm{NO}_{2}^{-}$is synergistic at killing $P A$ biofilms with the membrane disrupting agent colistimethate (polymyxin E) but inhibits the microbicidal activity of aminoglycosides (Zemke et al., 2015). In CF patients, Brown et al. (1985) showed that $\mathrm{NO}_{2}^{-}$at doses as high as $250 \mathrm{mM}$ were non-toxic. Based on the phenotypic evidence found associated with our PA4455 mutant, we believe that the gene product is important for the overall membrane stability associated with $P A$. It may be possible that without $P A 4455$, the membrane integrity is perturbed, thereby allowing the entrance of small molecules such as $\mathrm{NO}_{2}^{-}$that are 
normally not permitted full entry into the cell. This could explain the elevated transcriptional regulation of genes associated with anaerobic respiration in the PA4455 mutant.

\section{B-band LPS is Necessary for Anaerobic Growth and Optimal Resistance to A- $\mathrm{NO}_{2}^{-}$ and EDTA}

It has previously been shown that B-band LPS production is significantly reduced during anaerobic growth, while it is dramatically overproduced under oxidative stress conditions (e.g., exposure to $\mathrm{H}_{2} \mathrm{O}_{2}$; Sabra et al., 2003). The highly negatively charged form of B-band $\mathrm{O}$ antigen, known as B-band LPS, is necessary for formation of membrane vesicles inducible by oxidative stress in the form of $\mathrm{H}_{2} \mathrm{O}_{2}$ (Macdonald and Kuehn, 2013). Our results, unexpectedly, suggest that B-band LPS is critical not only for anaerobic growth of $P A$, but also for optimal resistance to EDTA and A- $\mathrm{NO}_{2}^{-}$. The molecular basis underlying this phenomenon is currently under study. In E. coli, a mutant lacking a PA4455 ABC transporter permease homolog, MlaE, was found to be exquisitely susceptible to EDTA/SDS and this was thought be to due to increased cellular permeabilization (Malinverni and Silhavy, 2009). One unique feature of the A- $\mathrm{NO}_{2}^{-}$and/or EDTA sensitivity of the various mutant strains used in this study was the consistent and very dramatic sensitivity of B-band LPS mutants.

\section{SUMMARY}

In summary, the discovery of $P A 4455$ as being a critical component in resistance to both $\mathrm{A}-\mathrm{NO}_{2}^{-}$and EDTA was unexpected, yet potentially intriguing for translational purposes. Given the promising results of this study, we believe that the combination of $\mathrm{A}_{-} \mathrm{NO}_{2}^{-}$and EDTA represents a novel combinatorial, non-toxic treatment that could potentially achieve the translational goal of eradicating nonmucoid and mucoid $P A$ (and potentially other organisms) in the CF and COPD airways.

\section{AUTHOR CONTRIBUTIONS}

Substantial contributions to the conception or design of the work; or the acquisition, analysis, or interpretation of data for the work
(CM, SS, WP, GL, TB, KC, AP, SK, JM, JL, DM, DH); drafting the work or revising it critically for important intellectual content (CM, SS, WP, GL, TB, KC, AP, SK, JM, JL, DM, DH); final approval of the version to be published (CM, SS, WP, GL, TB, KC, AP, SK, JM, JL, DM, DH); Agreement to be accountable for all aspects of the work in ensuring that questions related to the accuracy or integrity of any part of the work are appropriately investigated and resolved (CM, SS, WP, GL, TB, KC, AP, SK, JM, JL, DM, DH).

\section{FUNDING}

This work was supported primarily by a Merit Review Grant from the Department of Veteran's Affairs, Cincinnati VA Hospital (Cincinnati, OH). Additional support was from ARCH Biopartners, Inc. (Toronto, Canada), Cystic Fibrosis Research, Inc. (Mountain View, CA), Cure Finders, Inc. (Sevierville, TN), Aires Pharma (San Diego, CA), and the Daniel Tyler Health and Education Foundation (Fort Collins, CO).

\section{SUPPLEMENTARY MATERIAL}

The Supplementary Material for this article can be found online at: http://journal.frontiersin.org/article/10.3389/fmicb. 2016.00291

Supplementary Figure 1 | qPCR results of wild-type and mutant bacteria. RNA was extracted from late log phase growing organisms (PAO1, PA4455, and pUCP-PA4455), then subjected to (A) PCR and (B,C) RT-PCR. Primers against the middle regions of each shown gene were used. For RT-PCR, the reported values are fold increases for each gene in each mutant bacteria over values for PAO1 $\left(2^{\Delta \Delta} C_{T}\right)$. Initial $\Delta C_{T}$ measurements were calculated using each gene in the PA4455 operon compared to the housekeeping gene, acpP. (B) Aerobic- and (C) anaerobically grown organisms were both used for RT-PCR, and the averages of each samples $2^{\Delta \Delta} C_{T}$ values are reported.

Supplementary Figure 2 | Diagrams of the LPS profile of wild-type, $r m / C$, rmd, and wpbM mutant strains used in this study. Each sugar moiety is given in a short table inserted within the figure. OSA, O-specific antigen; CSA, cell surface antigen. Jagged black lines in the outer membrane (gray), lipid A. Adapted from Lam et al. (2011).

Supplementary Figure 3 | TEM of wild-type, PA4455 mutant and PA4455 mutant complemented strains during anaerobic growth. Sections were scanned for areas with predominant bacterial density, and images were taken at 100,000x magnification. (A) PAO1, (B) PA4455 mutant, (C) PA4455 mutant complemented with pUCP-PA4455.

\section{REFERENCES}

Alakomi, H. L., Paananen, A., Suihko, M. L., Helander, I. M., and Saarela, M. (2006). Weakening effect of cell permeabilizers on gram-negative bacteria causing biodeterioration. Appl. Environ. Microbiol. 72, 4695-4703. doi: 10.1128/AEM.00142-06

Al-Hamad, A., Upton, M., and Burnie, J. (2009). Molecular cloning and characterization of SmrA, a novel ABC multidrug efflux pump from Stenotrophomonas maltophilia. J. Antimicrob. Chemother. 64, 731-734. doi: 10.1093/jac/dkp271

Alvarez-Ortega, C., and Harwood, C. S. (2007). Responses of Pseudomonas aeruginosa to low oxygen indicate that growth in the cystic fibrosis lung is by aerobic respiration. Mol. Microbiol. 65, 153-165. doi: 10.1111/j.13652958.2007.05772.x

Arai, H., Igarashi, Y., and Kodama, T. (1995). Expression of the nir and nor genes for denitrification of Pseudomonas aeruginosa requires a novel CRP/FNRrelated transcriptional regulator, DNR, in addition to ANR. FEBS Lett. 371, 73-76. doi: 10.1016/0014-5793(95)00885-D

Barraud, N., Hassett, D. J., Hwang, S. H., Rice, S. A., Kjelleberg, S., and Webb, J. S. (2006). Involvement of nitric oxide in biofilm dispersal of Pseudomonas aeruginosa. J. Bacteriol. 188, 7344-7353. doi: 10.1128/JB.00 779-06

Boucher, R. C. (2002). An overview of the pathogenesis of cystic fibrosis lung disease. Adv. Drug Deliv. Rev. 54, 1359-1371. doi: 10.1016/S0169409X(02)00144-8

Brown, J., Mellis, C. M., and Wood, R. E. (1985). Edetate sodium aerosol in Pseudomonas lung infection in cystic fibrosis. Am. J. Dis. Child 139, 836-839. doi: 10.1001/archpedi.1985.02140100098043 
Caetano-Anolles, G. (1993). Amplifying DNA with arbitrary oligonucleotide primers. PCR Methods Appl. 3, 85-94. doi: 10.1101/gr.3.2.85

Champlin, F. R., Ellison, M. L., Bullard, J. W., and Conrad, R. S. (2005). Effect of outer membrane permeabilisation on intrinsic resistance to low triclosan levels in Pseudomonas aeruginosa. Int. J. Antimicrob. Agents 26, 159-164. doi: 10.1016/j.ijantimicag.2005.04.020

Choi, D. S., Kim, D. K., Choi, S. J., Lee, J., Choi, J. P., Rho, S., et al. (2011). Proteomic analysis of outer membrane vesicles derived from Pseudomonas aeruginosa. Proteomics 11, 3424-3429. doi: 10.1002/pmic.201000212

Coakley, R. D., Grubb, B. R., Paradiso, A. M., Gatzy, J. T., Johnson, L. G., Kreda, S. M., et al. (2003). Abnormal surface liquid $\mathrm{pH}$ regulation by cultured cystic fibrosis bronchial epithelium. Proc. Natl. Acad. Sci. U.S.A. 100, 16083-16088. doi: 10.1073/pnas.2634339100

Creuzenet, C., and Lam, J. S. (2001). Topological and functional characterization of WbpM, an inner membrane UDP-GlcNAc C6 dehydratase essential for lipopolysaccharide biosynthesis in Pseudomonas aeruginosa. Mol. Microbiol. 41, 1295-1310. doi: 10.1046/j.1365-2958.2001.02589.x

Dong, C., Major, L. L., Srikannathasan, V., Errey, J. C., Giraud, M. F., Lam, J. S., et al. (2007). RmlC, a C3' and C5' carbohydrate epimerase, appears to operate via an intermediate with an unusual twist boat conformation. J. Mol. Biol. 365, 146-159. doi: 10.1016/j.jmb.2006.09.063

Farinha, M. A., and Helinski, A. M. (1990). Construction of broad-host-range plasmid vectors for easy visible selection and analysis of promoters. J. Bacteriol. 172, 3496-3499.

Govan, J. R. W., and Deretic, V. (1996). Microbial pathogenesis in cystic fibrosis: mucoid Pseudomonas aeruginosa and Burkholderia cepacia. Microbiol. Rev. 60, 539-574.

Hao, Y., Hwang, S., Zhang, S., Kim, E., Akinbi, H. T., Schurr, M. J., et al. (2011). The Pseudomonas aeruginosa flagellum confers resistance to pulmonary surfactant protein-A by impacting the production of exoproteases through quorumsensing. Mol. Microbiol. 79, 1220-1235. doi: 10.1111/j.1365-2958.2010.07516.x

Hassett, D. J. (1996). Anaerobic production of alginate by Pseudomonas aeruginosa: alginate restricts diffusion of oxygen. J. Bacteriol. 178, 7322-7325.

Hassett, D. J., Borchers, M. T., and Panos, R. J. (2014). Chronic obstructive pulmonary disease (COPD): evaluation from clinical, immunological and bacterial pathogenesis perspectives. J. Microbiol. 52, 211-226. doi: 10.1007/s12275-014-4068-2

Hentzer, M., Teitzel, G. M., Balzer, G. J., Heydorn, A., Molin, S., Givskov, M., et al. (2001). Alginate overproduction affects Pseudomonas aeruginosa biofilm structure and function. J. Bacteriol. 183, 5395-5401. doi: 10.1128/JB.183.18.5395-5401.2001

Higgins, C. F. (1992). ABC transporters: from microorganisms to man. Ann. Rev. Cell Biol. 8, 67-113. doi: 10.1146/annurev.cb.08.110192.000435

Hoang, T. T., Kutchma, A. J., Becher, A., and Schweizer, H. P. (2000). Integrationproficient plasmids for Pseudomonas aeruginosa: site-specific integration and use for engineering of reporter and expression strains. Plasmid 43, 59-72. doi: 10.1006/plas.1999.1441

Holloway, B. W., Krishnapillai, V., and Morgan, A. F. (1979). Chromosomal genetics of Pseudomonas. Microbiol. Rev. 43, 73-102.

Kim, Y. M., Farrah, S., and Baney, R. H. (2007). Structure-antimicrobial activity relationship for silanols, a new class of disinfectants, compared with alcohols and phenols. Int. J. Antimicrob. Agents 29, 217-222. doi: 10.1016/j.ijantimicag.2006.08.036

Kolpen, M., Kuhl, M., Bjarnsholt, T., Moser, C., Hansen, C. R., Liengaard, L., et al. (2014). Nitrous oxide production in sputum from cystic fibrosis patients with chronic Pseudomonas aeruginosa lung infection. PLoS ONE 9:e84353. doi: 10.1371/journal.pone. 0084353

Kulasekara, H. D., Ventre, I., Kulasekara, B. R., Lazdunski, A., Filloux, A., and Lory, S. (2005). A novel two-component system controls the expression of Pseudomonas aeruginosa fimbrial cup genes. Mol. Microbiol. 55, 368-380. doi: $10.1111 /$ j.1365-2958.2004.04402.x

Lam, J. S., Taylor, V. L., Islam, S. T., Hao, Y., and Kocincova, D. (2011). Genetic and functional diversity of pseudomonas aeruginosa lipopolysaccharide. Front. Microbiol. 2:118. doi: 10.3389/fmicb.2011.00118

Lau, G. W., Britigan, B. E., and Hassett, D. J. (2005). Pseudomonas aeruginosa OxyR is required for full virulence in rodent and insect models of infection and for resistance to human neutrophils. Infect. Immun. 73, 2550-2553. doi: 10.1128/IAI.73.4.2550-2553.2005
Lenz, A. P., Williamson, K. S., Pitts, B., Stewart, P. S., and Franklin, M. J. (2008), Localized gene expression in Pseudomonas aeruginosa biofilms. Appl. Environ. Microbiol. 74, 4463-4471. doi: 10.1128/AEM.00710-08

Livak, K. J., and Schmittgen, T. D. (2001). Analysis of relative gene expression data using real-time quantitative PCR and the 2(-Delta Delta C(T)) Method. Methods 25, 402-408. doi: 10.1006/meth.2001.1262

Macdonald, I. A., and Kuehn, M. J. (2013). Stress-induced outer membrane vesicle production by Pseudomonas aeruginosa. J. Bacteriol. 195, 2971-2981. doi: 10.1128/JB.02267-12

MacKenzie, T., Gifford, A. H., Sabadosa, K. A., Quinton, H. B., Knapp, E. A., Goss, C. H., et al. (2014). Longevity of patients with cystic fibrosis in 2000 to 2010 and beyond: survival analysis of the cystic fibrosis foundation patient registry. Ann. Intern. Med. 161, 233-241. doi: 10.7326/M13-0636

Major, T. A., Panmanee, W., Mortensen, J. E., Gray, L. D., Hoglen, N., and Hassett, D. J. (2010). Sodium nitrite-mediated killing of the major cystic fibrosis pathogens Pseudomonas aeruginosa, Staphylococcus aureus, and Burkholderia cepacia under anaerobic planktonic and biofilm conditions. Antimicrob. Agents Chemother. 54, 4671-4677. doi: 10.1128/AAC.00379-10

Malinverni, J. C., and Silhavy, T. J. (2009). An ABC transport system that maintains lipid asymmetry in the gram-negative outer membrane. Proc. Natl. Acad. Sci. U.S.A. 106, 8009-8014. doi: 10.1073/pnas.0903229106

Maniatis, T., Fritsch, E. F., and Sambrook, J. (1982). Molecular Cloning: a Laboratory Manual. Cold Spring Harbor, NY: Cold Spring Harbor Laboratory.

Martin, D. W., Schurr, M. J., Mudd, M. H., Govan, J. R., Holloway, B. W., and Deretic, V. (1993). Mechanism of conversion to mucoidy in Pseudomonas aeruginosa infecting cystic fibrosis patients. Proc. Natl. Acad. Sci. U.S.A. 90, 8377-8381. doi: 10.1073/pnas.90.18.8377

Matsushita, K., Adachi, O., Shinagawa, E., and Ameyama, M. (1978). Isolation and characterization of outer and inner membranes from Pseudomonas aeruginosa and effect of EDTA on the membranes. J. Biochem. 83, 171-181.

Meshulam, T., Obedeanu, N., Merzbach, D., and Sobel, J. D. (1984). Phagocytosis of mucoid and nonmucoid strains of Pseudomonas aeruginosa. Clin. Immunol. Immunopathol. 32, 151-165. doi: 10.1016/0090-1229(84)90117-X

Miller, J. H. (1992). A Short Course in Bacterial Genetics. A Laboratory Manual and Handbook for Escherichia coli and Related Bacteria. Plainview, NY: Cold Spring Harbor Laboratory Press.

Murphy, K., Park, A. J., Hao, Y., Brewer, D., Lam, J. S., and Khursigara, C. M. (2014). Influence of O polysaccharides on biofilm development and outer membrane vesicle biogenesis in Pseudomonas aeruginosa PAO1. J. Bacteriol. 196, 1306-1317. doi: 10.1128/JB.01463-13

Murphy, T. F., Brauer, A. L., Eschberger, K., Lobbins, P., Grove, L., Cai, X., et al. (2008). Pseudomonas aeruginosa in chronic obstructive pulmonary disease. Am. J. Respir. Crit. Care Med. 177, 853-860. doi: 10.1164/rccm.200709-1413OC

O’May, C. Y., Sanderson, K., Roddam, L. F., Kirov, S. M., and Reid, D. W. (2009). Iron-binding compounds impair Pseudomonas aeruginosa biofilm formation, especially under anaerobic conditions. J. Med. Microbiol. 58, 765-773. doi: 10.1099/jmm.0.004416-0

Pletzer, D., Braun, Y., Dubiley, S., Lafon, C., Kohler, T., Page, M. G., et al. (2015). The Pseudomonas aeruginosa PA14 ABC transporter NppA1A2BCD is required for uptake of peptidyl nucleoside antibiotics. J. Bacteriol. 197, 2217-2228. doi: 10.1128/JB.00234-15

Rahim, R., Burrows, L. L., Monteiro, M. A., Perry, M. B., and Lam, J. S. (2000). Involvement of the $\mathrm{rml}$ locus in core oligosaccharide and $\mathrm{O}$ polysaccharide assembly in Pseudomonas aeruginosa. Microbiology 146 (Pt 11), 2803-2814. doi: 10.1099/00221287-146-11-2803

Reilman, E., Mars, R. A., van Dijl, J. M., and Denham, E. L. (2014). The multidrug $\mathrm{ABC}$ transporter $\mathrm{BmrC} / \mathrm{BmrD}$ of Bacillus subtilis is regulated via a ribosome-mediated transcriptional attenuation mechanism. Nucleic Acids Res. 42, 11393-11407. doi: 10.1093/nar/gku832

Rocchetta, H. L., Burrows, L. L., Pacan, J. C., and Lam, J. S. (1998a). Three rhamnosyltransferases responsible for assembly of the A-band D-rhamnan polysaccharide in Pseudomonas aeruginosa: a fourth transferase, WbpL, is required for the initiation of both A-band and B-band lipopolysaccharide synthesis. Mol. Microbiol. 28, 1103-1119.

Rocchetta, H. L., Pacan, J. C., and Lam, J. S. (1998b). Synthesis of the A-band polysaccharide sugar D-rhamnose requires Rmd and WbpW: identification of multiple AlgA homologues, WbpW and ORF488, in Pseudomonas aeruginosa. Mol. Microbiol. 29, 1419-1434. 
Sabra, W., Lunsdorf, H., and Zeng, A. P. (2003). Alterations in the formation of lipopolysaccharide and membrane vesicles on the surface of Pseudomonas aeruginosa PAO1 under oxygen stress conditions. Microbiology 149, 2789-2795. doi: $10.1099 /$ mic. $0.26443-0$

Schweizer, H. P. (1991). Escherichia-Pseudomonas shuttle vectors derived from pUC18/19. Gene 97, 109-121. doi: 10.1016/0378-1119(91)90016-5

Schweizer, H. P. (1992). Allelic exchange in Pseudomonas aeruginosa using novel ColE1-type vectors and a family of cassettes containing a portable oriT and the counter-selectable Bacillus subtilis sacB marker. Mol. Microbiol. 6, 1195-1204. doi: 10.1111/j.1365-2958.1992.tb01558.x

Schweizer, H. P. (1993). Small broad-host-range gentamicin resistance gene cassettes for site-specific insertion and deletion mutagenesis. Biotechniques 15, 831-833.

Schweizer, H. P., and Hoang, T. T. (1995). An improved system for gene replacement and $x y l E$ fusion analysis in Pseudomonas aeruginosa. Gene 158, 15-22. doi: 10.1016/0378-1119(95)00055-B

Sherman, D. J., Okuda, S., Denny, W. A., and Kahne, D. (2013). Validation of inhibitors of an $\mathrm{ABC}$ transporter required to transport lipopolysaccharide to the cell surface in Escherichia coli. Bioorg. Med. Chem. 21, 4846-4851. doi: 10.1016/j.bmc.2013.04.020

Simon, R., Priefer, U., and Puehler, A. (1983). A broad host range mobilization system for in vivo genetic engineering: transposon mutagenesis in gram negative bacteria. Nat. Bio Technol. 1, 784-791. doi: 10.1038/nbt 1183-784

Su, S., Panmanee, W., Wilson, J. J., Mahtani, H. K., Li, Q., Vanderwielen, B. D., et al. (2014). Catalase (KatA) plays a role in protection against anaerobic nitric oxide in Pseudomonas aeruginosa. PLoS ONE 9:e91813. doi: 10.1371/journal.pone.0091813

Tunney, M. M., Field, T. R., Moriarty, T. F., Patrick, S., Doering, G., Muhlebach, M. S., et al. (2008). Detection of anaerobic bacteria in high numbers in sputum from patients with cystic fibrosis. Am. J. Respir. Crit. Care Med. 177, 995-1001. doi: 10.1164/rccm.200708-11510C

Valderrey, A. D., Pozuelo, M. J., Jimenez, P. A., Macia, M. D., Oliver, A., and Rotger, R. (2010). Chronic colonization by Pseudomonas aeruginosa of patients with obstructive lung diseases: cystic fibrosis, bronchiectasis, and chronic obstructive pulmonary disease. Diagn. Microbiol. Infect. Dis. 68, 20-27. doi: 10.1016/j.diagmicrobio.2010.04.008

Woldringh, C. L., and van Iterson, W. (1972). Effects of treatment with sodium dodecyl sulfate on the ultrastructure of Escherichia coli. J. Bacteriol. 111, 801-813.

Wood, R. E., Klinger, J. D., Thomassen, M. J., and Cash, H. A. (1980). "The effect of EDTA and antibiotics on Pseudomonas aeruginosa isolated from cystic fibrosis patients: a new chemotherapeutic approach," in Perspectives in Cystic Fibrosis, ed J. M. Sturgess (Toronto, ON: Canadian Cystic Fibrosis Foundation), 365-369.
Worlitzsch, D., Tarran, R., Ulrich, M., Schwab, U., Cekici, A., Meyer, K. C., et al (2002). Reduced oxygen concentrations in airway mucus contribute to the early and late pathogenesis of Pseudomonas aeruginosa cystic fibrosis airway infection. J. Clin. Invest. 109, 317-325. doi: 10.1172/JCI0213870

Yoon, S. S., Coakley, R., Lau, G. W., Lymar, S. V., Gaston, B., Karabulut, A. C., et al. (2006). Anaerobic killing of mucoid Pseudomonas aeruginosa by acidified nitrite derivatives under cystic fibrosis airway conditions. J. Clin. Invest. 116, 436-446. doi: 10.1172/JCI24684

Yoon, S. S., Hennigan, R. F., Hilliard, G. M., Ochsner, U. A., Parvatiyar, K., Kamani, M. C., et al. (2002). Pseudomonas aeruginosa anaerobic respiration in biofilms: relationships to cystic fibrosis pathogenesis. Dev. Cell 3, 593-603. doi: 10.1016/S1534-5807(02)00295-2

Yoon, S. S., Karabulut, A. C., Lipscomb, J. D., Hennigan, R. F., Lymar, S. V., Groce, S. L., et al. (2007). Two-pronged survival strategy for the major cystic fibrosis pathogen, Pseudomonas aeruginosa, lacking the capacity to degrade nitric oxide during anaerobic respiration. EMBO J. 26, 3662-3672. doi: 10.1038/sj.emboj.7601787

Zemke, A. C., Gladwin, M. T., and Bomberger, J. M. (2015). Sodium nitrite blocks the activity of aminoglycosides against Pseudomonas aeruginosa biofilms. Antimicrob. Agents Chemother. 59, 3329-3334. doi: 10.1128/AAC.00546-15

Zemke, A. C., Shiva, S., Burns, J. L., Moskowitz, S. M., Pilewski, J. M., Gladwin, M. T., et al. (2014). Nitrite modulates bacterial antibiotic susceptibility and biofilm formation in association with airway epithelial cells. Free Radic. Biol. Med. 77, 307-316. doi: 10.1016/j.freeradbiomed.2014.08.011

Zhang, S., Chen, Y., Potvin, E., Sanschagrin, F., Levesque, R. C., McCormack, F. X., et al. (2005). Comparative signature-tagged mutagenesis identifies pseudomonas factors conferring resistance to the pulmonary collectin SP-A. PLoS Pathog. 1:e31. doi: 10.1371/journal.ppat.0010031

Conflict of Interest Statement: The authors declare that the research was conducted in the absence of any commercial or financial relationships that could be construed as a potential conflict of interest.

The authors received Research funding from Arch Biopartners Inc. to help conduct the study. DH and DM are insiders and have an equity position in Arch Biopartners Inc. DH has an issued patent (US 8,557,300 B2) and provisional patent application pertaining to the submitted work.

Copyright (C) 2016 McDaniel, Su, Panmanee, Lau, Browne, Cox, Paul, Ko, Mortensen, Lam, Muruve and Hassett. This is an open-access article distributed under the terms of the Creative Commons Attribution License (CC BY). The use, distribution or reproduction in other forums is permitted, provided the original author(s) or licensor are credited and that the original publication in this journal is cited, in accordance with accepted academic practice. No use, distribution or reproduction is permitted which does not comply with these terms. 